\title{
المسؤولية المدنية للسلطة التشريعية عن الخطأ في تشريعاتها
}

(در استة تحليلية مقارنة السئة

Doi: 10.23918/ilic2020.26

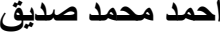 \\ مدرس القانون المدني \\ جامعة كركوك / كلية القانون والعلوم السياسية \\ ahmed.siddiq@uokirkuk.edu.iq
}

\section{المقدمة}

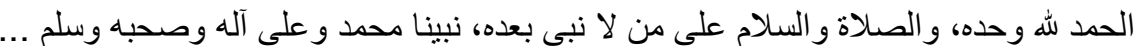

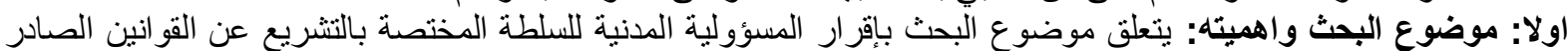

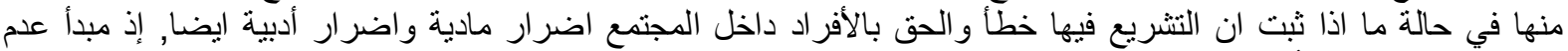

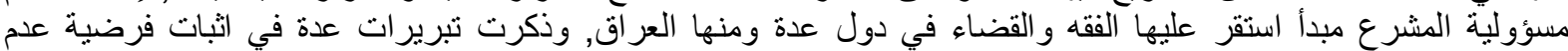

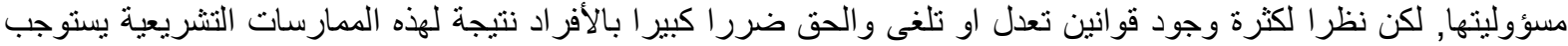

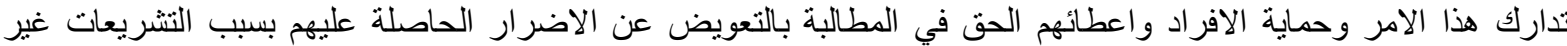

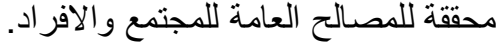

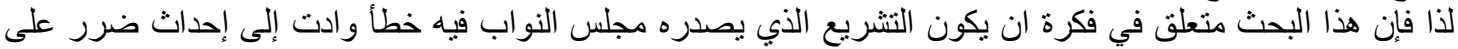

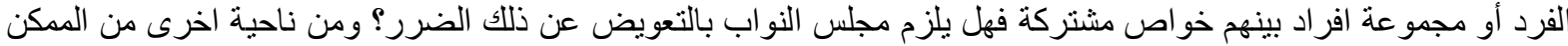

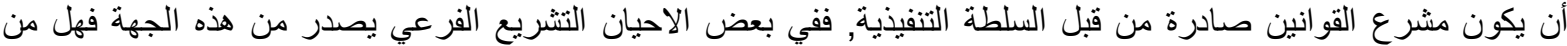

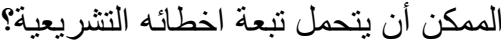
ثانيا: هدف البحث: نحاول في هذا البحث تطبيق احكام المسؤولية المدنية على المشرع في حالة ثبوت اصدئ المدار تشريع فيها خطأ او

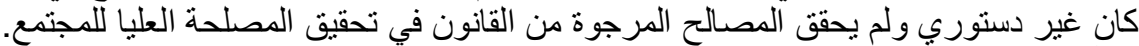

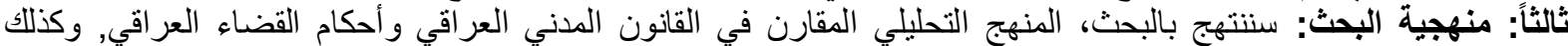

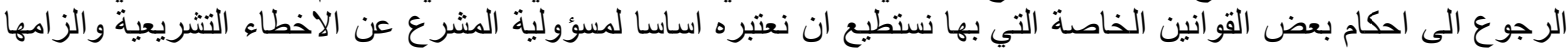

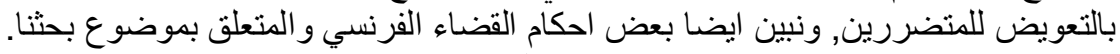

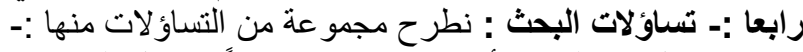

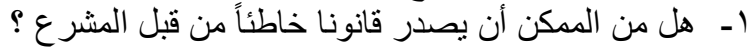

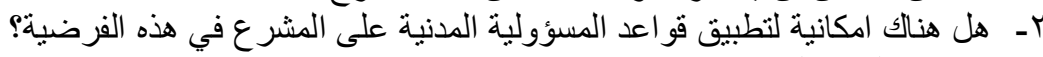

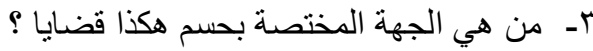

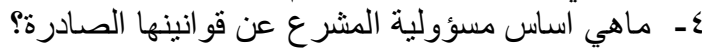

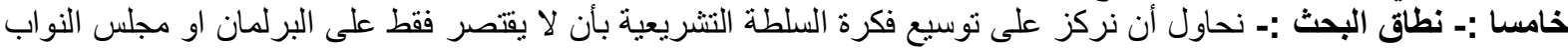

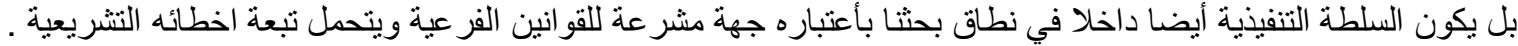

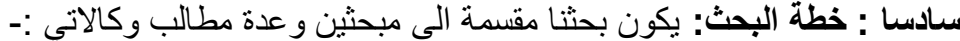
المبحث الأول :- مفهوم المشرع ون واساس مسؤوليتها عن الخطأ في تثريعاتها المطلب الأول :- مفهوم المشرع :- مفوم المثرع

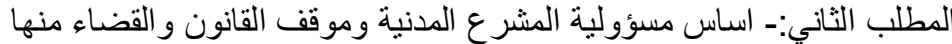

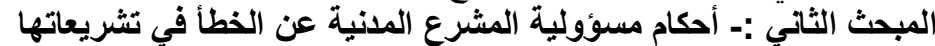

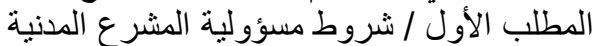

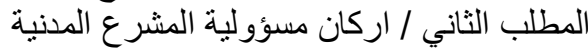
المبحث الأول المطلب الثالث / دعوى مسؤولية المشرع المنرع المدنية

مفهوم المشرع واساس مسؤوليتها عن الخطأ في تثريعاتها

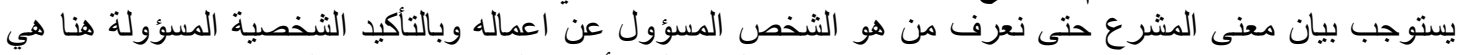

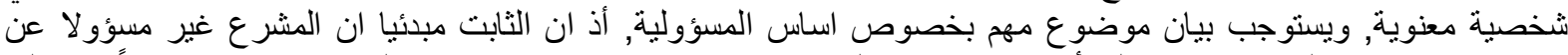

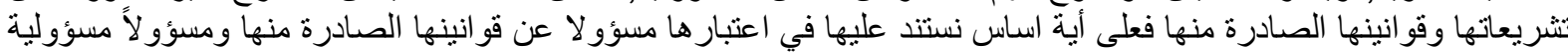

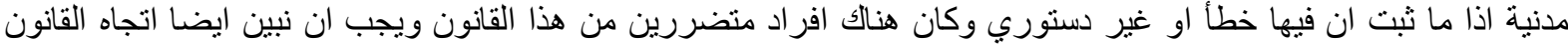

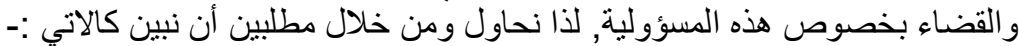
المطلب الأول :- مفهوم المشرع المشورية

المطلب الثاني:- اساس مسؤولية المشرع المثرع المدنية واتجاه القانون والقضاء منها 


\section{المثلب الأول

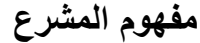

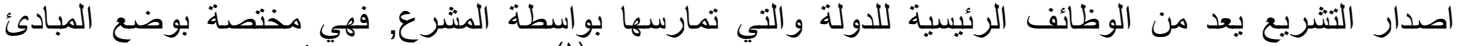

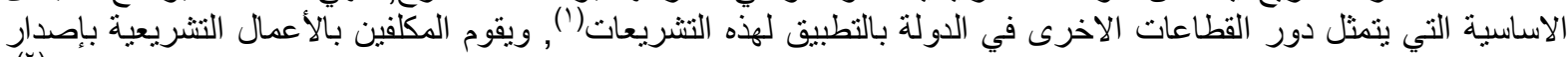

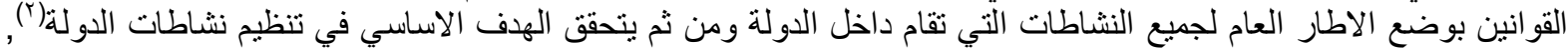

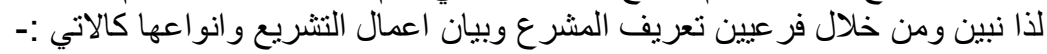

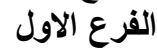
تعريف المشرع الاول

يعرف المشرع بأنها الجهة التي تمتلك صلاحية اصدار القاعدة القانونية الالزامية تحكم سلوكيات وتصرفات الافراد

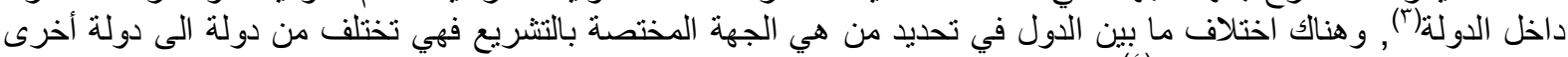

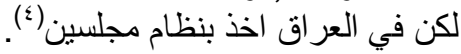

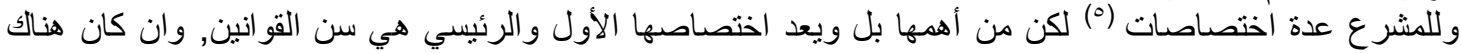

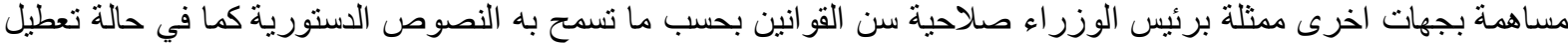

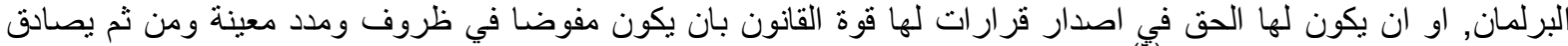

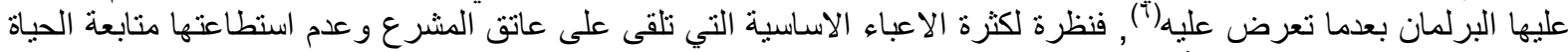

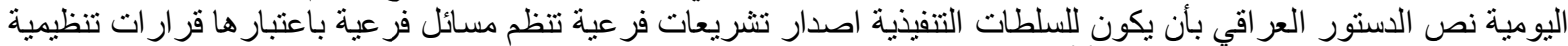

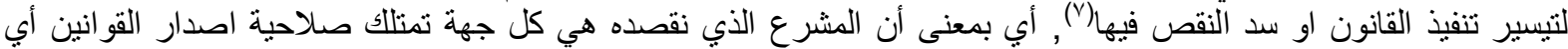

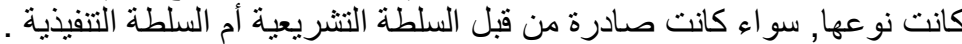

\section{الفرع الثناني

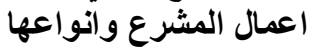

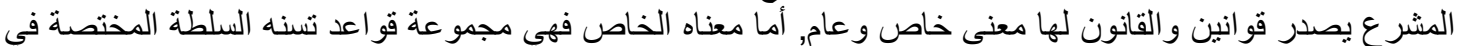

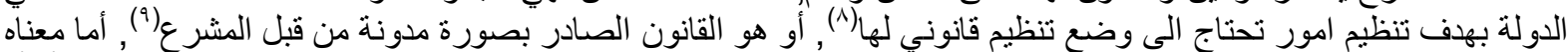

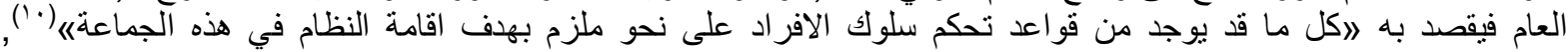

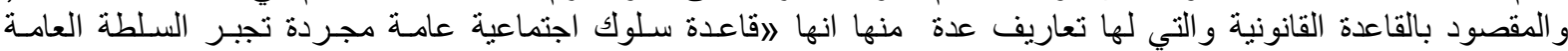

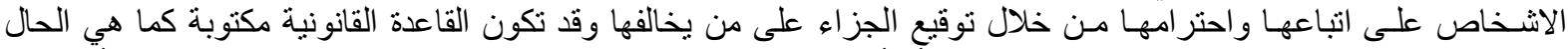

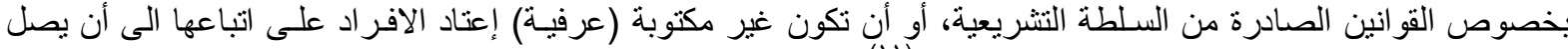

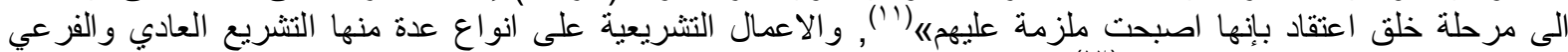

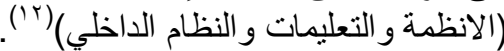

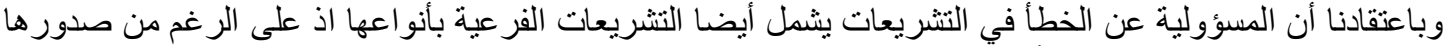

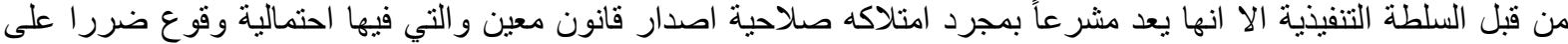
الافر اد فيما إذا كان فيها خطأ تشريعيا .

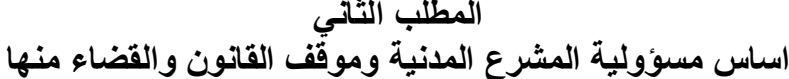

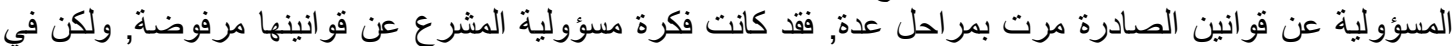

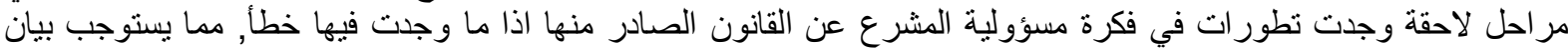

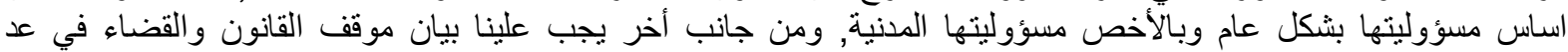

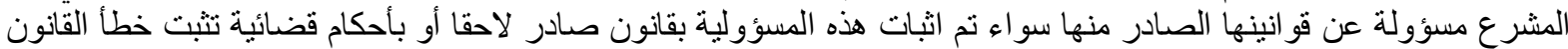
الصادر, و هذا ما تكون عليه خطة بحثنا في الفرعيين الآتيين وكالاتي :-

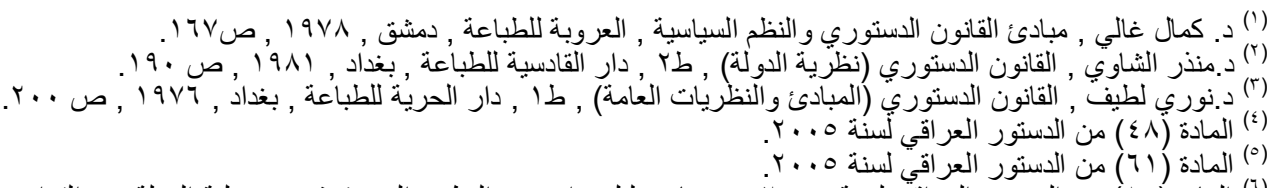

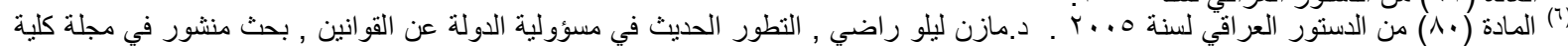

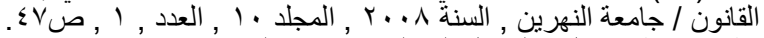

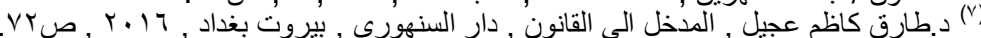

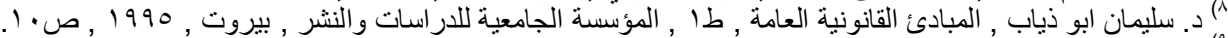

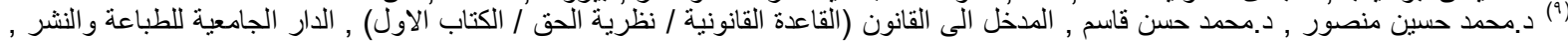
19 19...

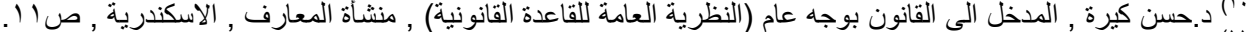

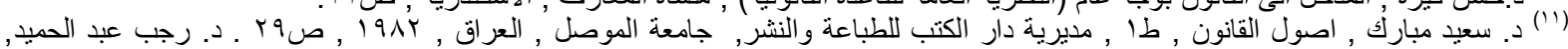

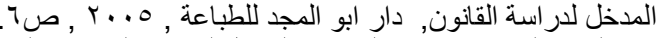

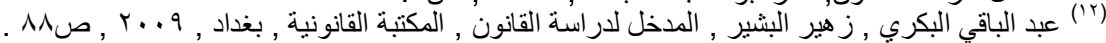




\section{الفرع الأول \\ اسل مساس مسؤلية المشرع المدانية}

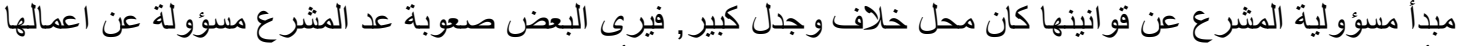

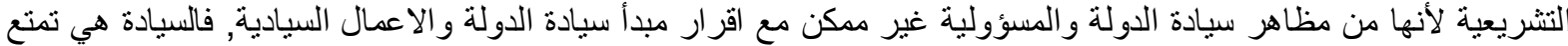

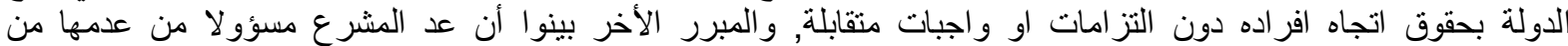

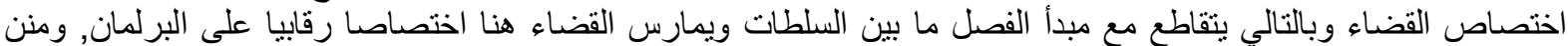

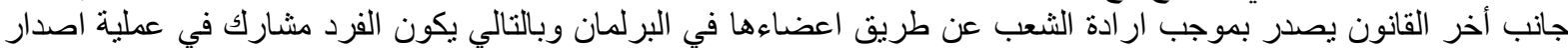

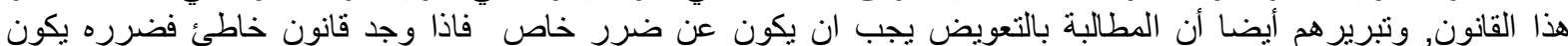

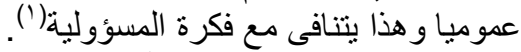

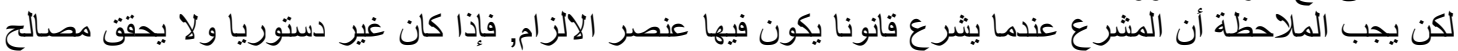

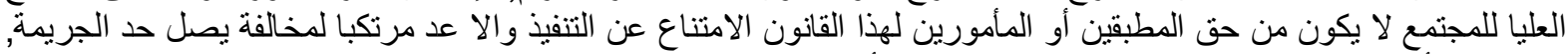

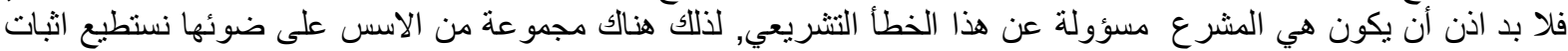

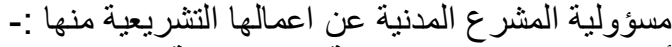
أولا :- اساس تلازم السلطة والمسؤولية :- لاعن يمكن أن تقوم المسؤولية إلا إذا كانت هنالك سلطة فكلاهما (السلطة و المسؤولية)

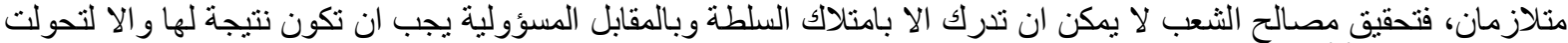

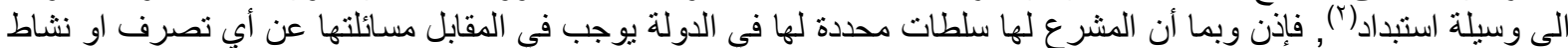

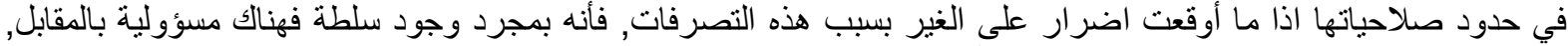

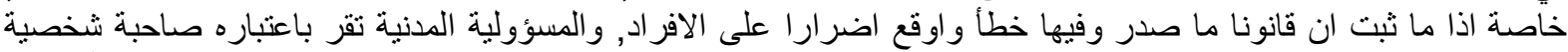

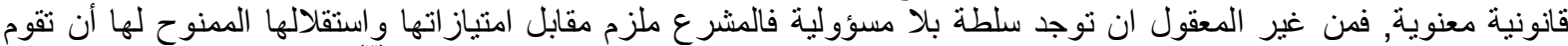

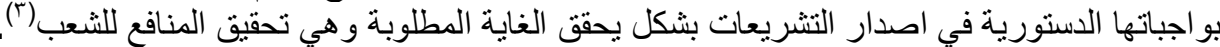

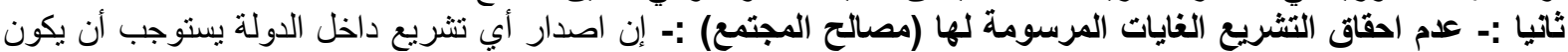

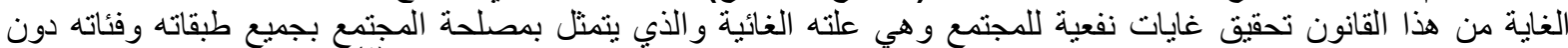

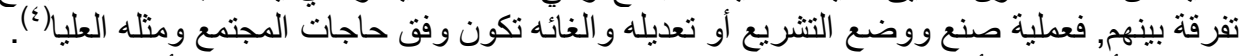

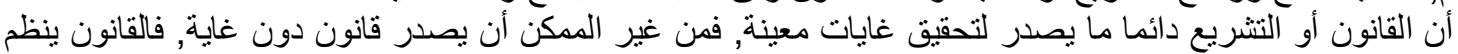

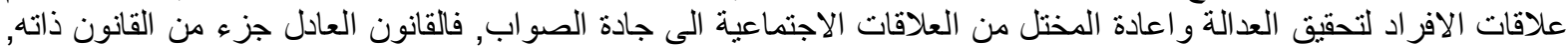

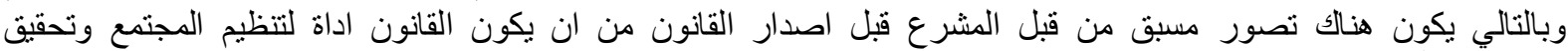

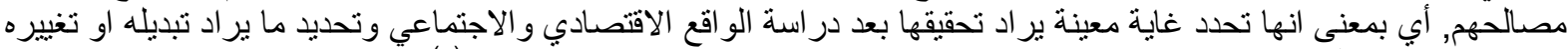

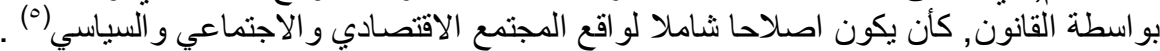

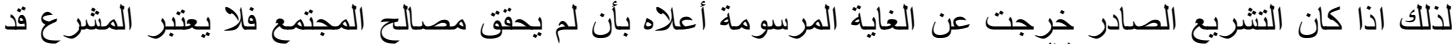

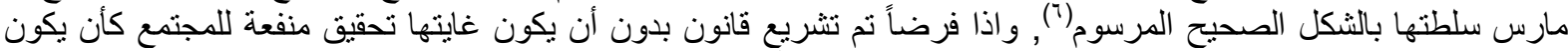

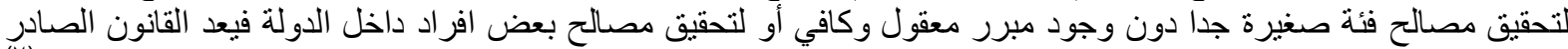

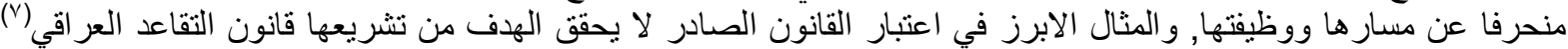

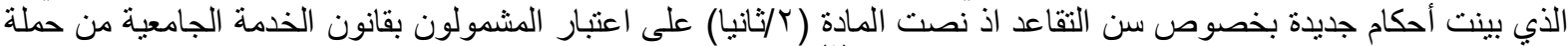

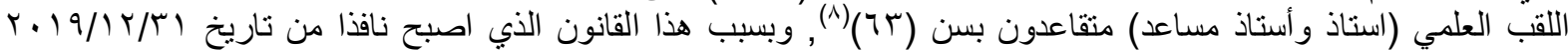

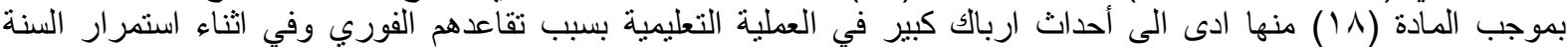

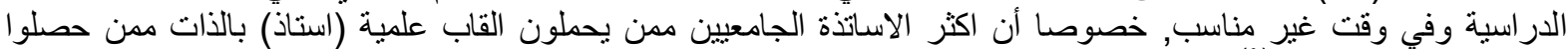

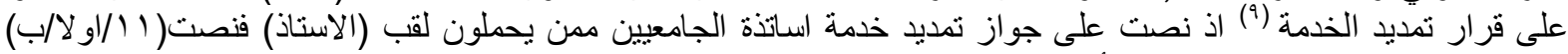
من قانون الخدمة الجامعية العر اقي بأنه اللوزير تمديد خدمة حامل لقب الاستاذية من الاختصاصات النادرة من شرط العمر

(') د. عمر السيوى , مسئولية الدولة عن القوانين , بحث منشور في موقع المكتبة القانونية العربية إناريخ الزيارة

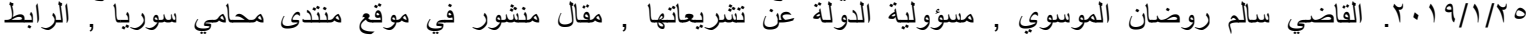

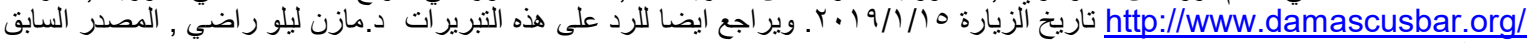

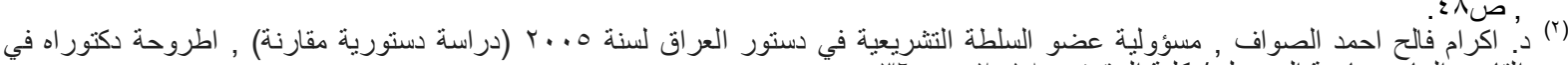

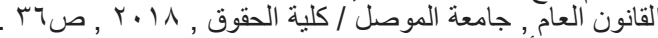

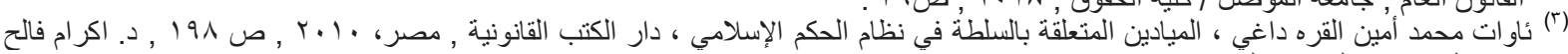

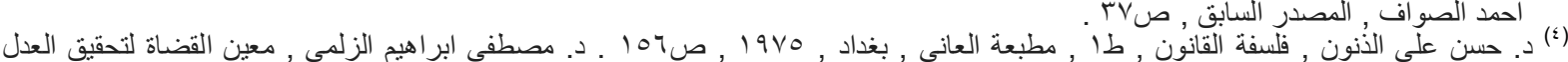

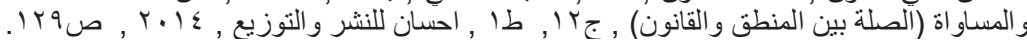

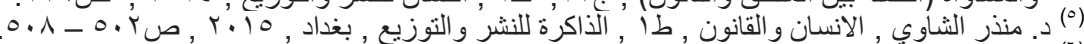

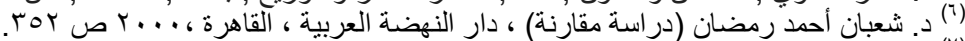

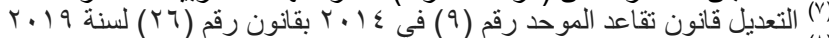

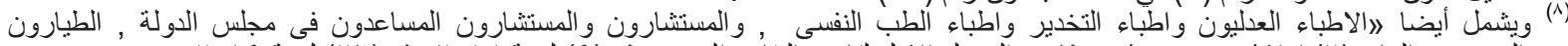

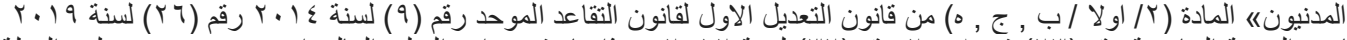

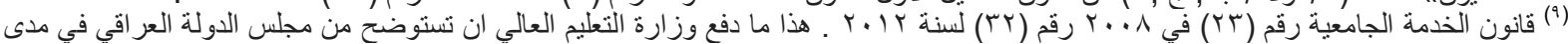

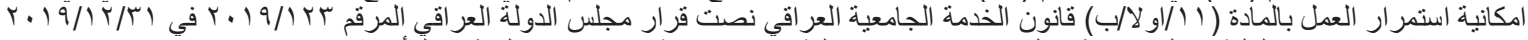

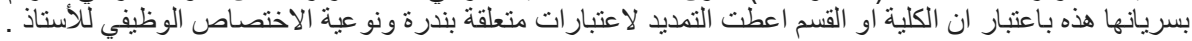




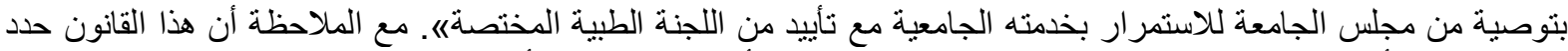

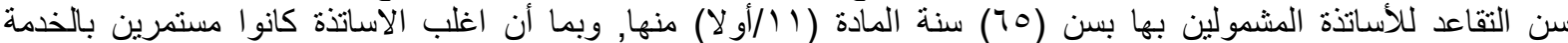

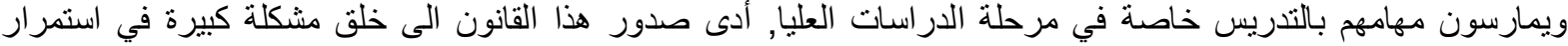

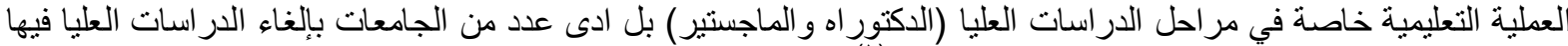

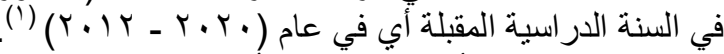

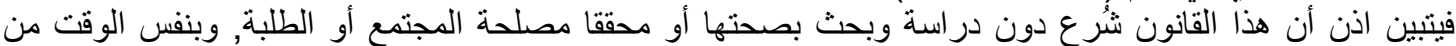

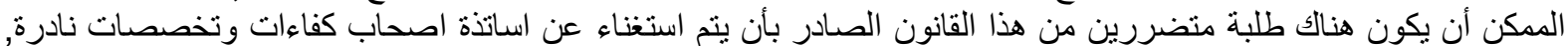

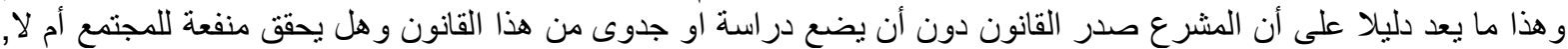

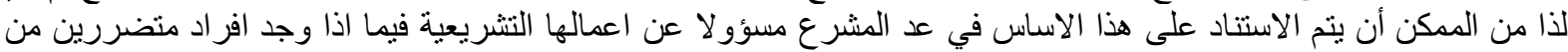

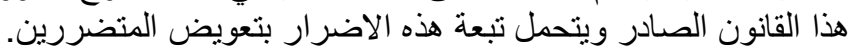

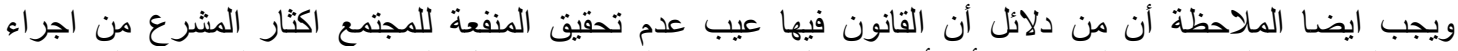

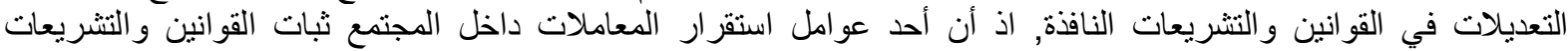

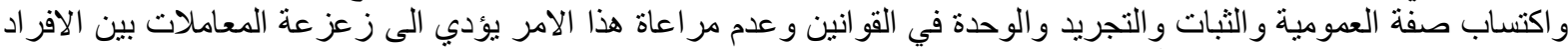
و عدم استقر ار ها بل ومن الممكن أن يكون هنالك اشخاص متضررين نتيجة لهذا التعديل المتكرر للقانون ـ التهن الفرع الثاني نئي

موقف القانون والقضاء في مسؤولية المشرع عن الخطأ في تثريعاتها

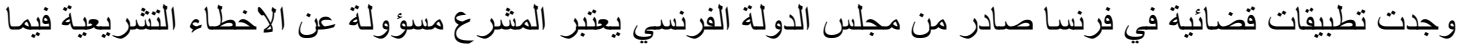

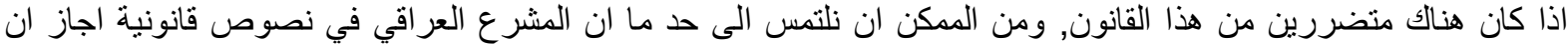

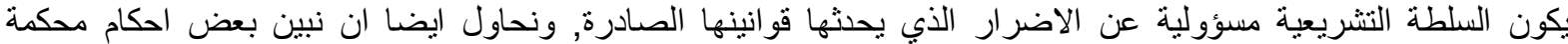

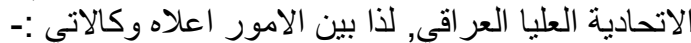

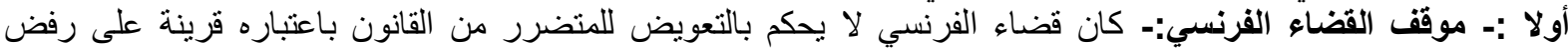

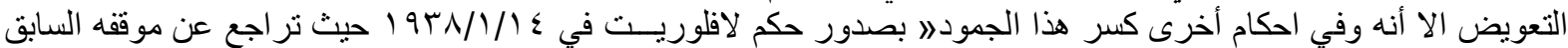

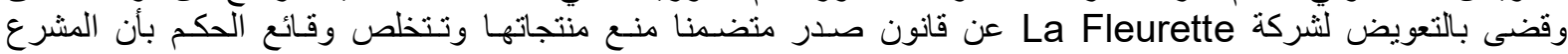

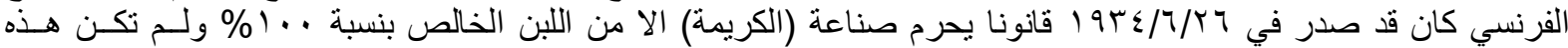

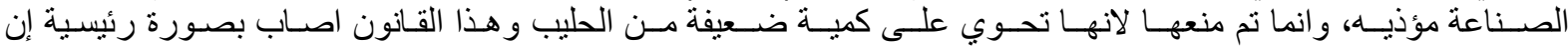

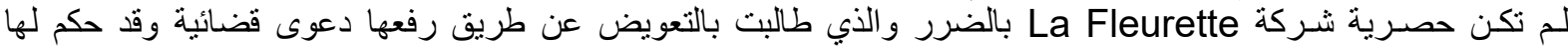

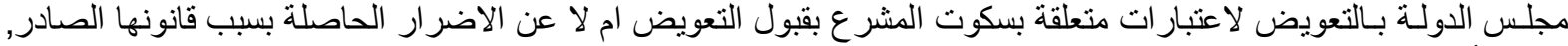

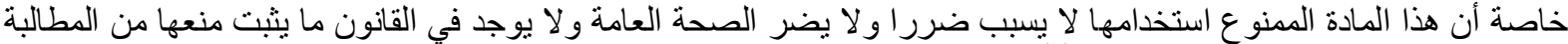

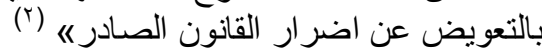

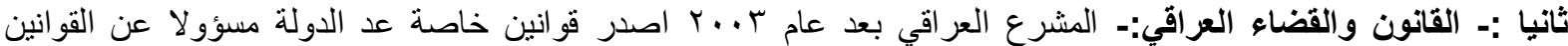

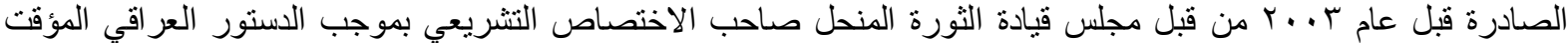

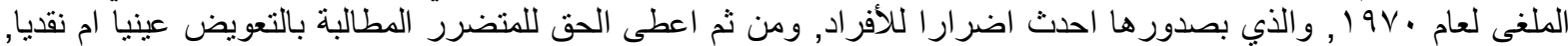

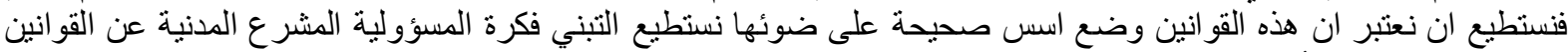

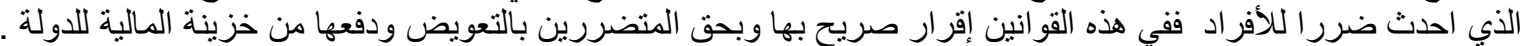

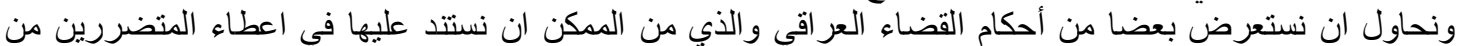

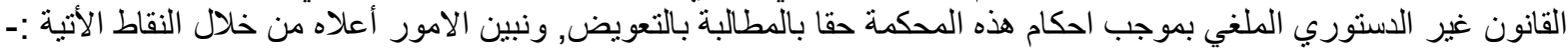

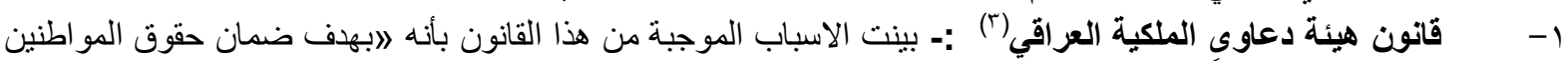

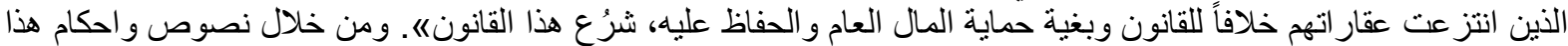

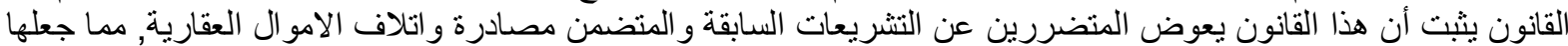
مسؤو لا عن ممارسات السلطة التشريعية .

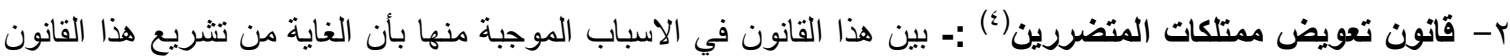

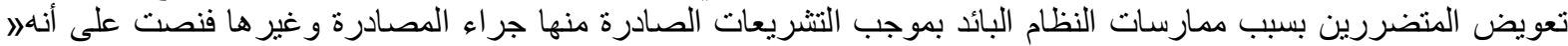

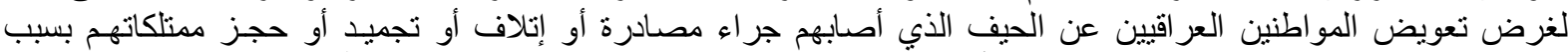

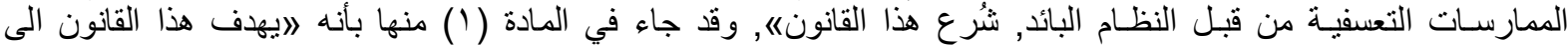

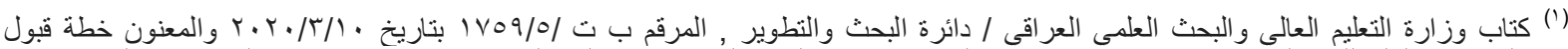

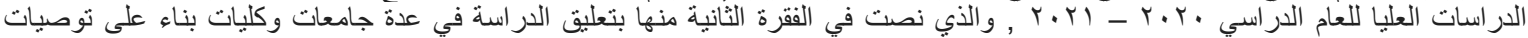

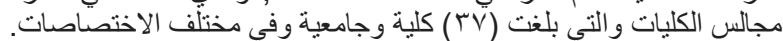

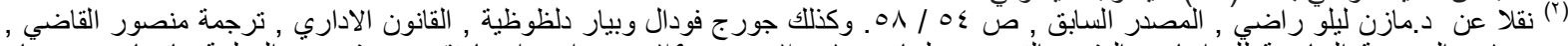

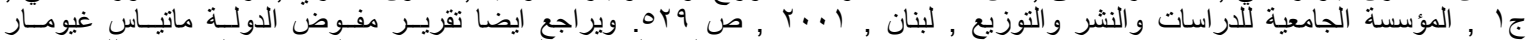

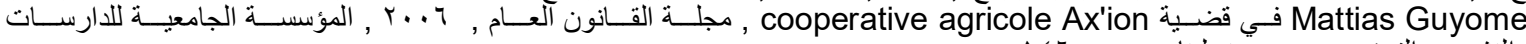

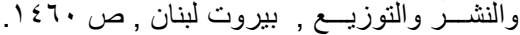

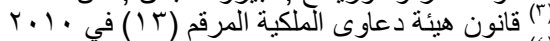

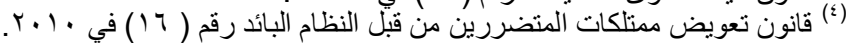




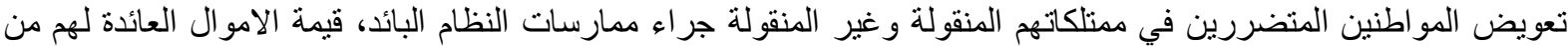

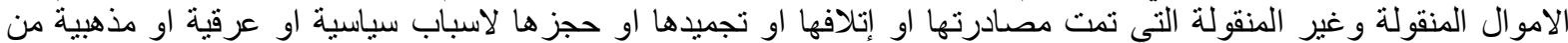

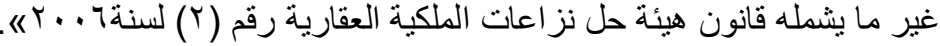

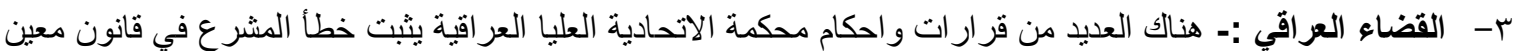

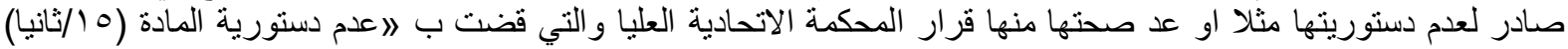

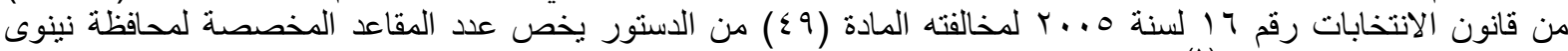

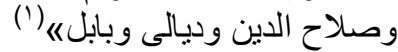

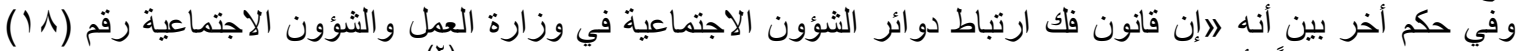

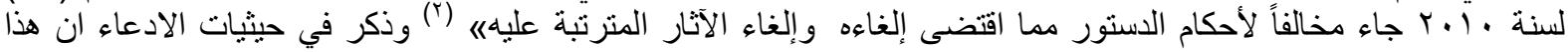

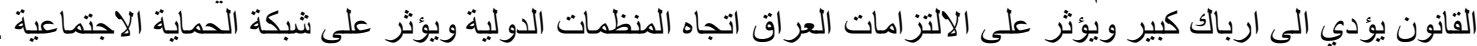

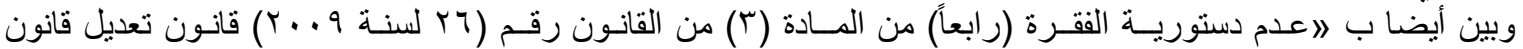

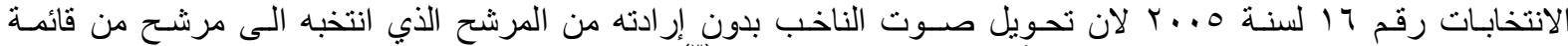

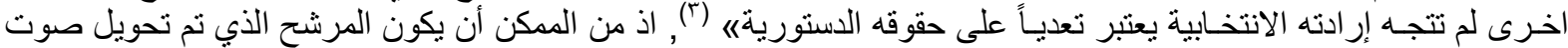

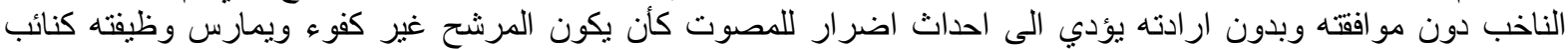

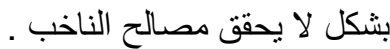

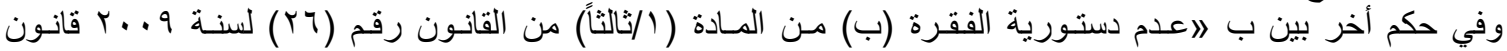

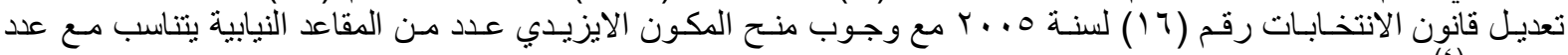

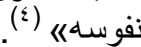

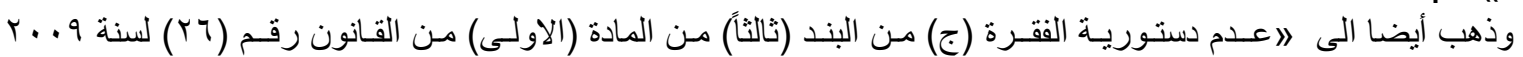

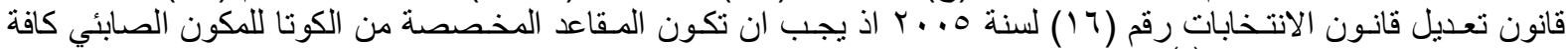

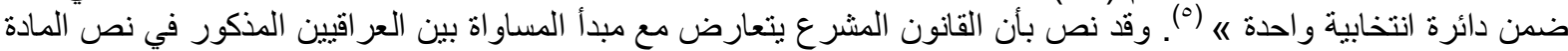

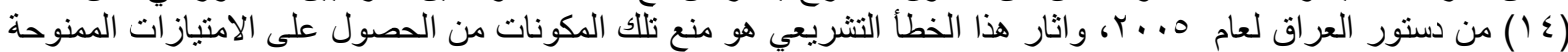

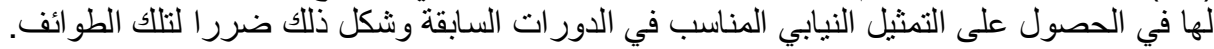
المبحث الثاني المني

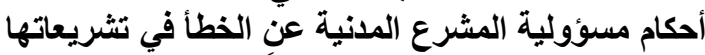

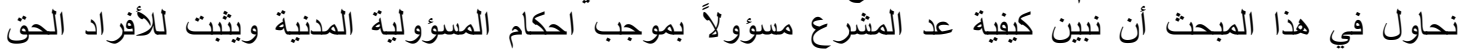

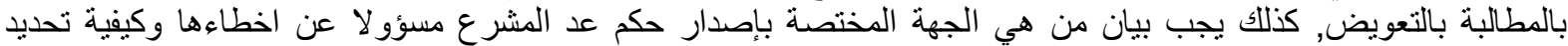
التعويض, ويجب كذلك بيان احكام التعويض, لذا نبان نبين في هذا المبحث كافة النقاط المثارة اعلاه وذلك من خلال ثلاثة مطالب,

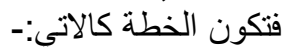
المطلب الأول / شروط مسؤولية المشرع المون المدنية

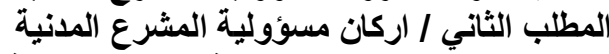
المطلب الثالثّ / دعوى مسؤولية المشروع المثرع المدنية

المطلب الأول

شروط مسؤولية المشرع المولبة المدنية

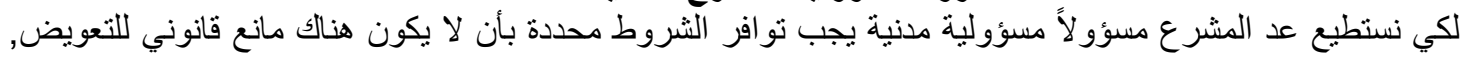

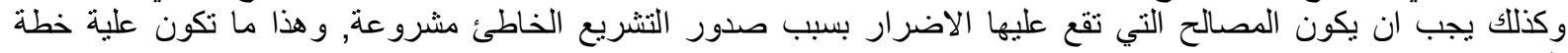

\section{الفرع الأول}

البحث وفي فرعيين كالاتي:-

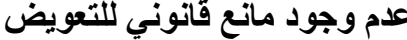

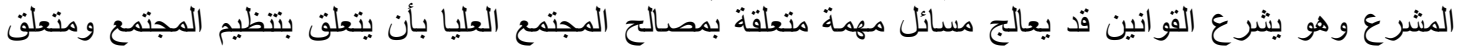

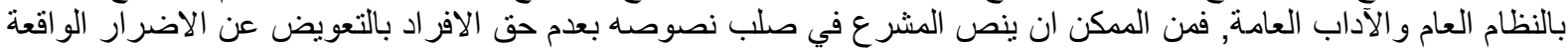

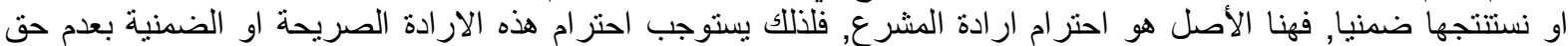

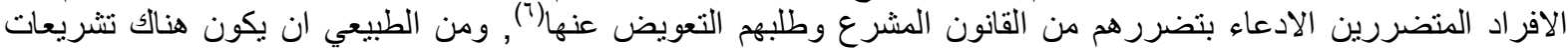

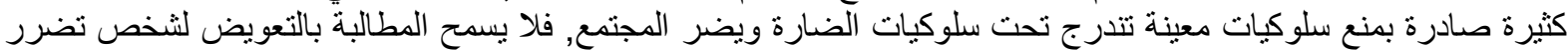
من تطبيق هذه القو انين .

https://www.iraqfsc.iq/ - ذي العدد 0

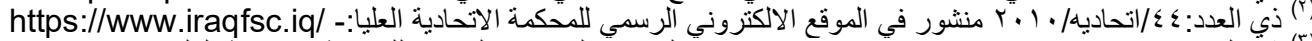

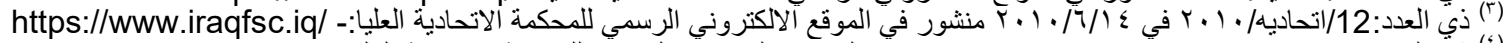

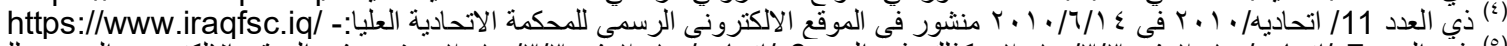

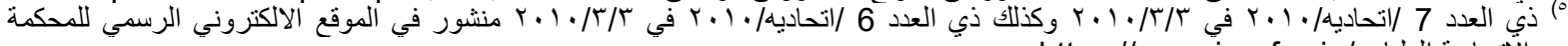

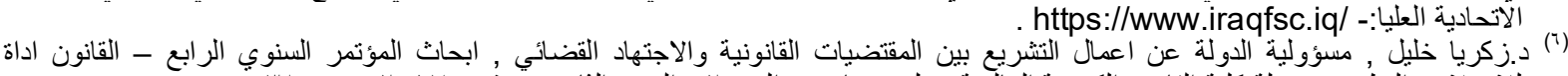

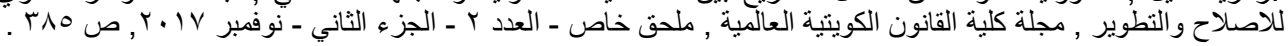




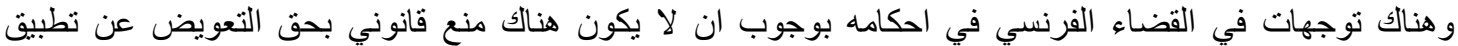

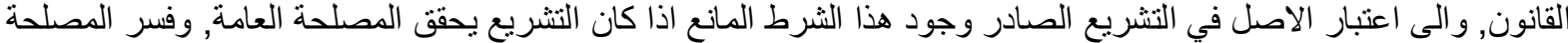

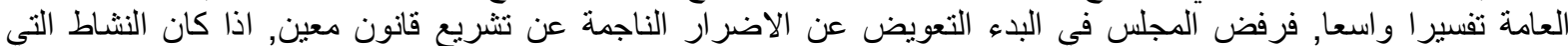

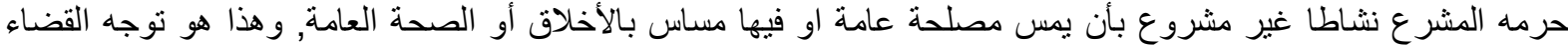

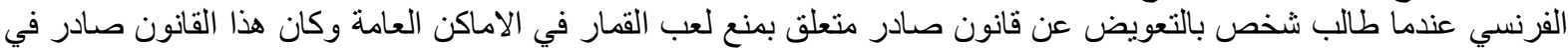

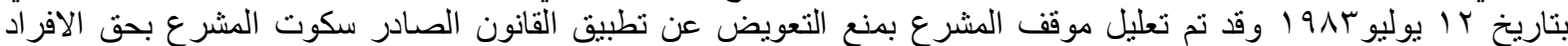

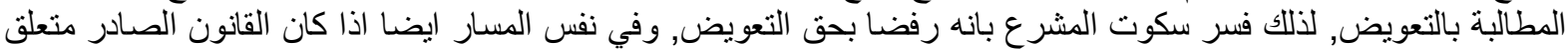

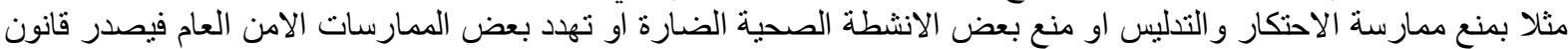

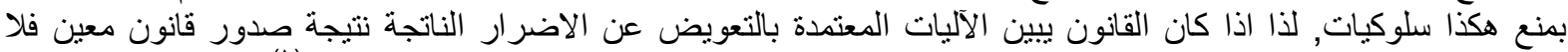

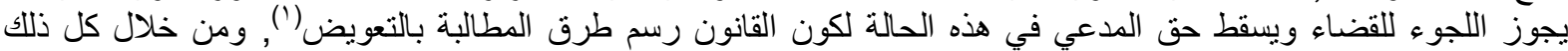

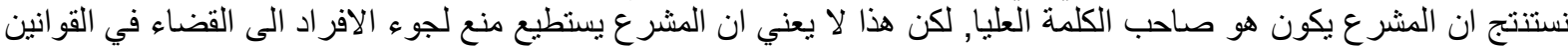
التي لا تكون متعلقة بالدصالح العليا.

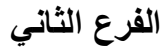 \\ المشروعية في المصالح الؤأقعة عليها الضرر}

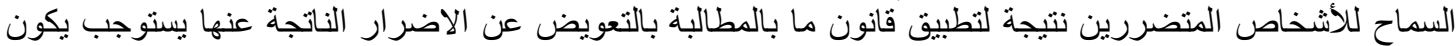

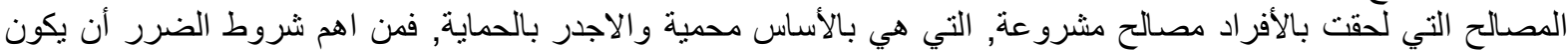

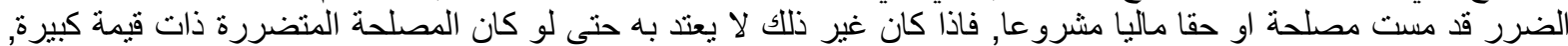

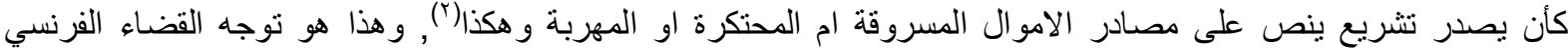

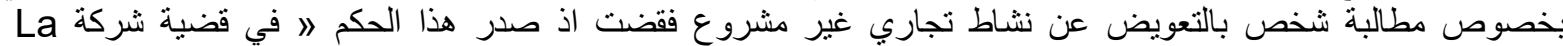

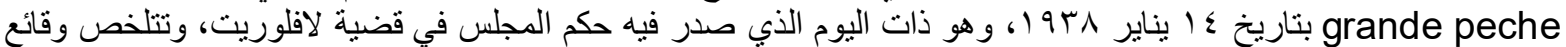

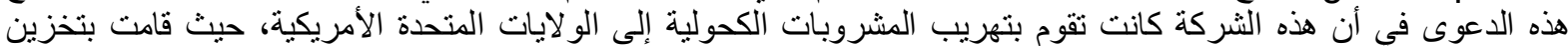

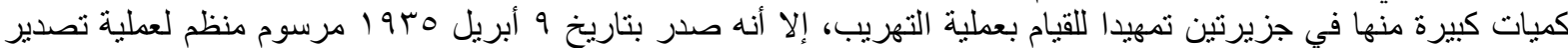

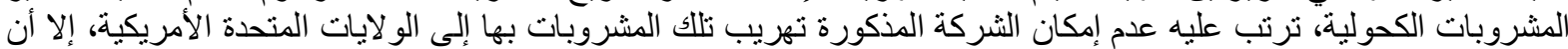

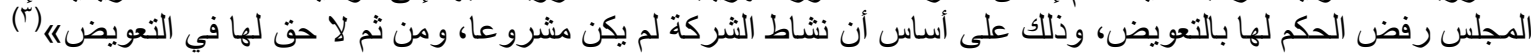

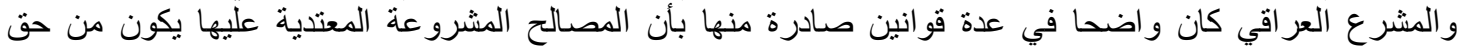

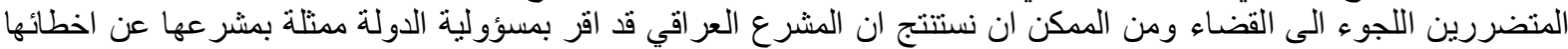

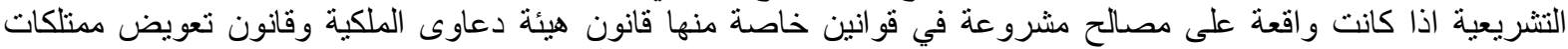

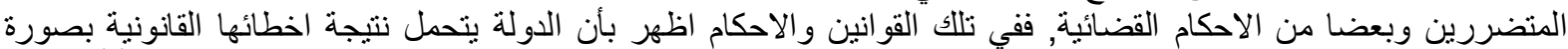

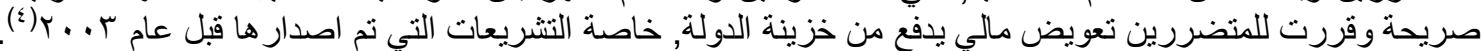
المطلب الثناني

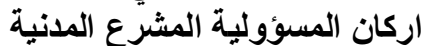

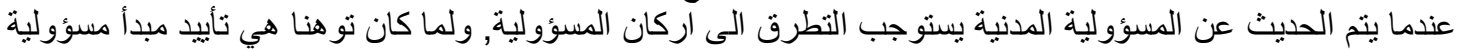

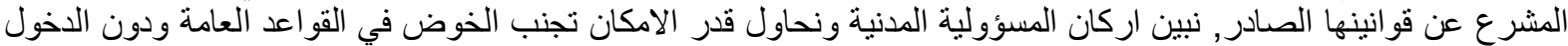

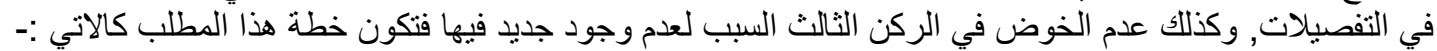

الفرع الأول

ركن الخطأ

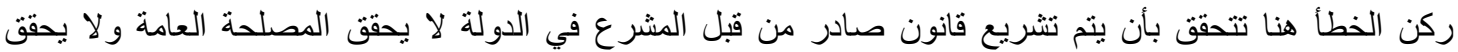
مصالح اغلبية الثعب, بل من الممكن ان يكون التشريع الصادر ضار البان بالمتمع غير محقى لاي منافع لها, طريقة اصدار مثل لإن

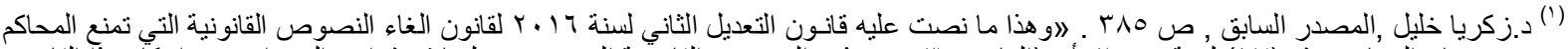

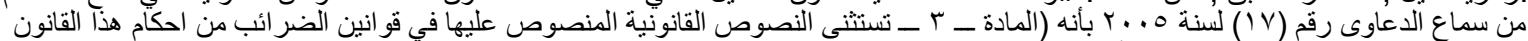

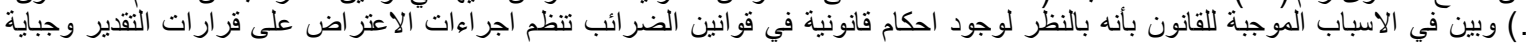

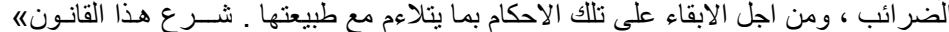

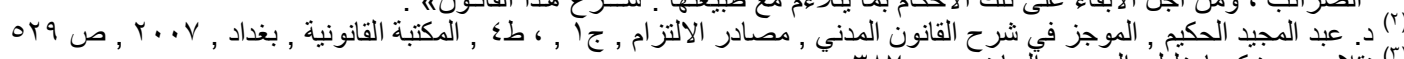

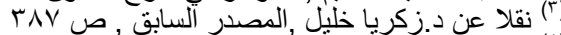

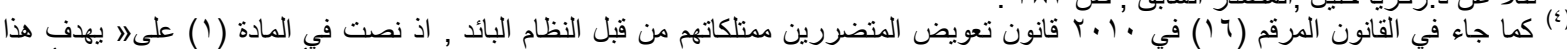

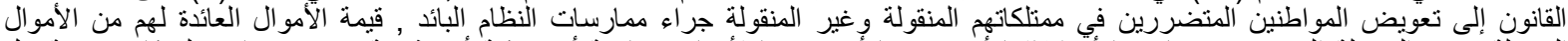

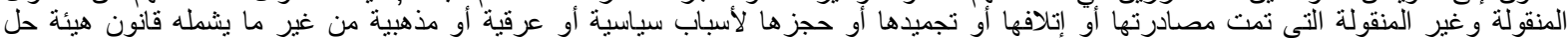

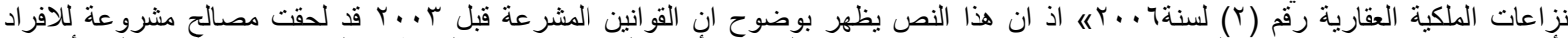

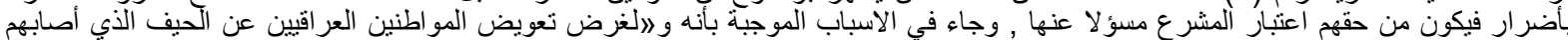

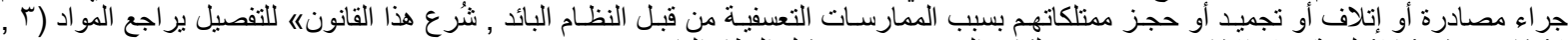

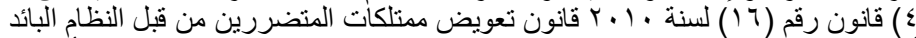

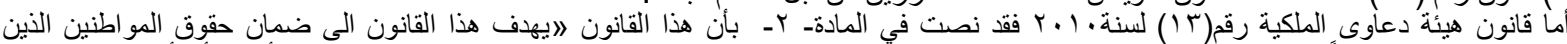

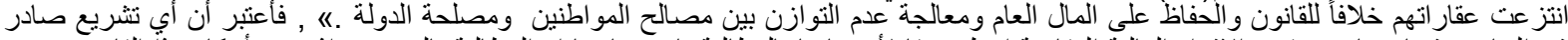

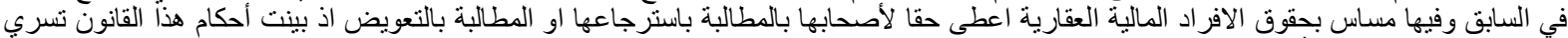

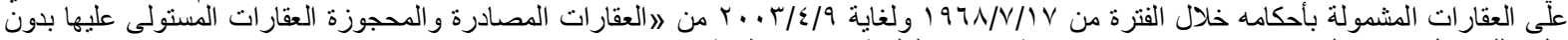

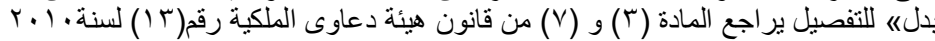


هكذا قانون من الطبيعي ان تتتج مسؤولية المشرع عن هذا التشريع, والخطأ هي اي فعل يصدر ناتج عن علم و ادر الك سو اء بقصد

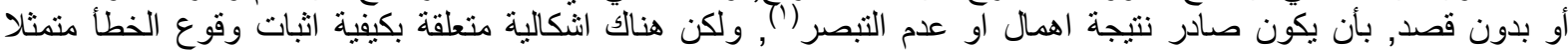

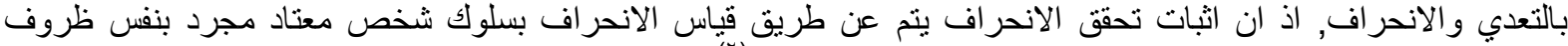

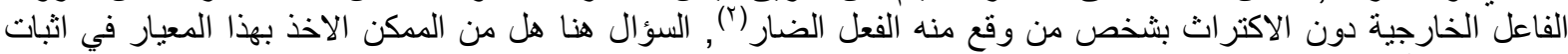

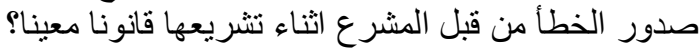

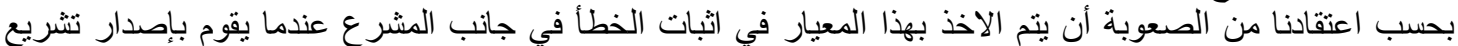

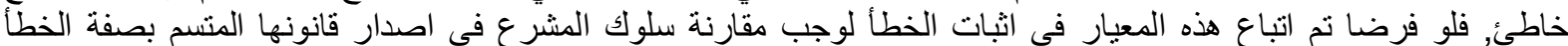

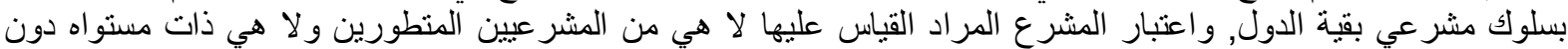

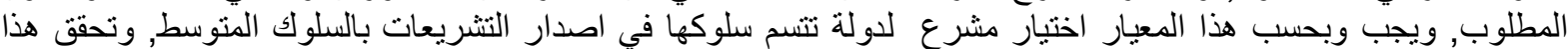

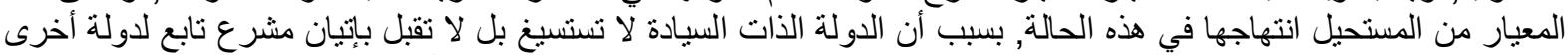

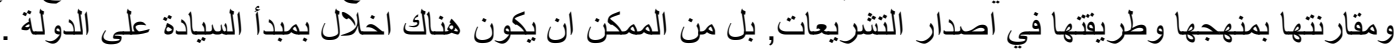

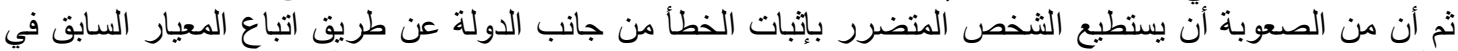

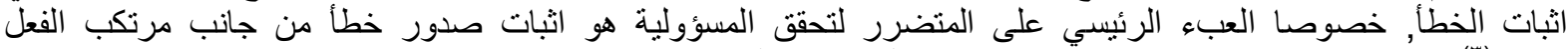

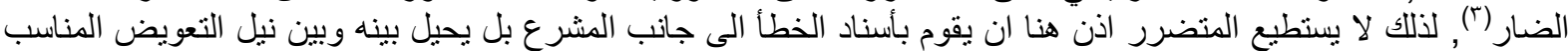

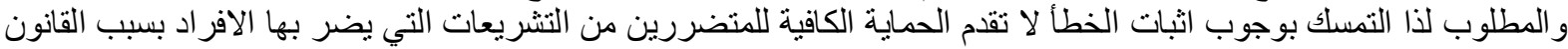
الخاطئ.

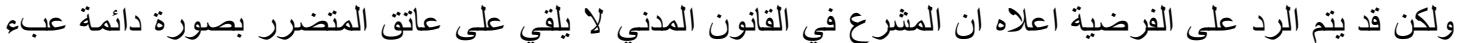

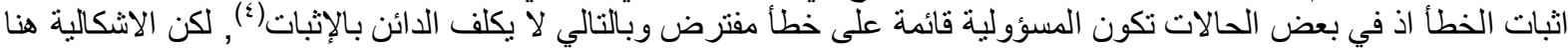

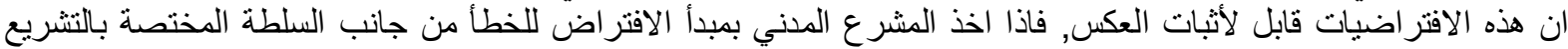

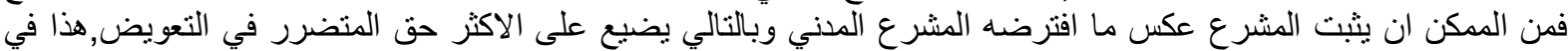

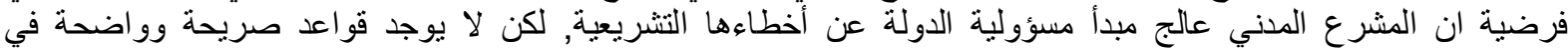

الافتر اضيات السابقة.

\section{الفرع الثاني \\ ركن الضرز}

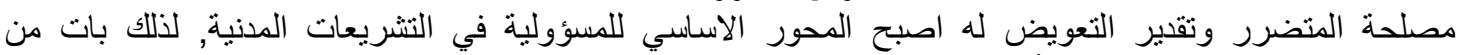

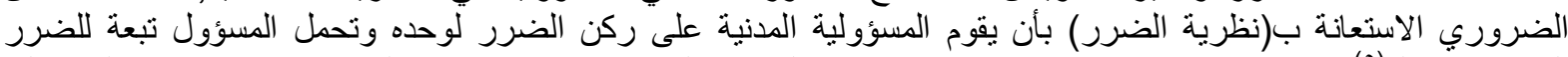

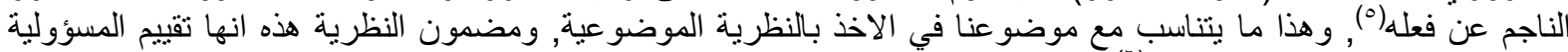

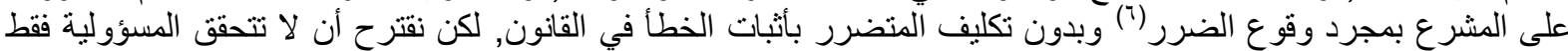

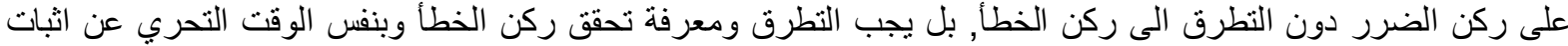

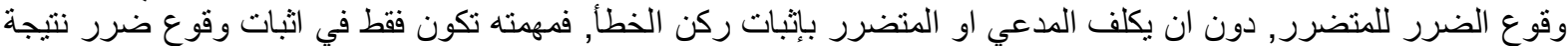

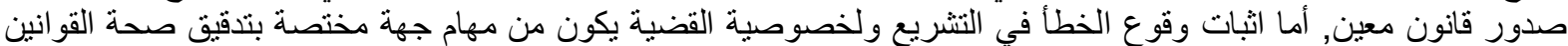

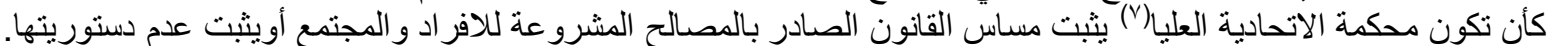

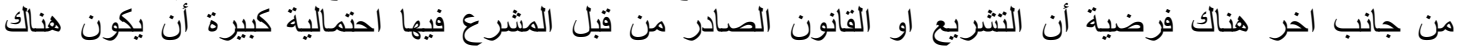

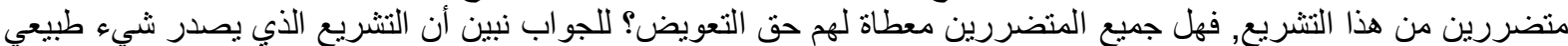

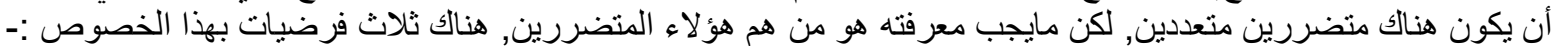

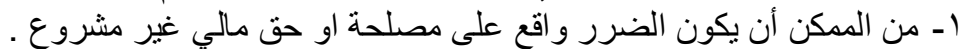

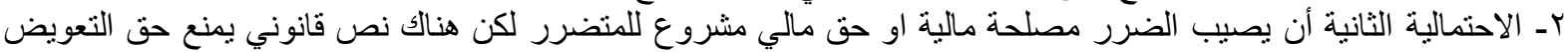

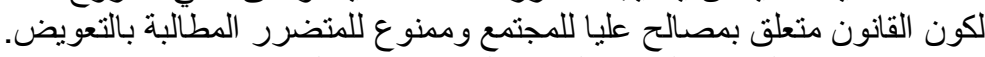

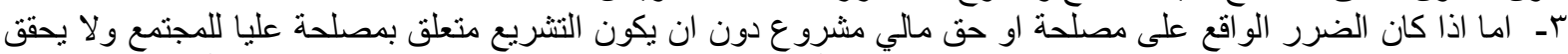
منفعة حقيقة للمجتمع, ففي هذه الحالة من المفضل اللجوء الى أن يكون المعيار في المسؤولية هي الضرر اي مبدأ تحمل التبعة.

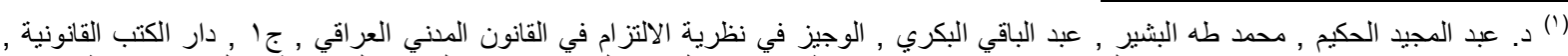

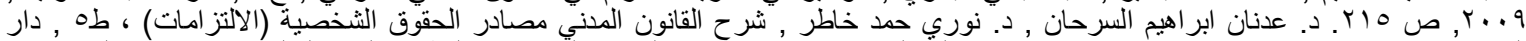

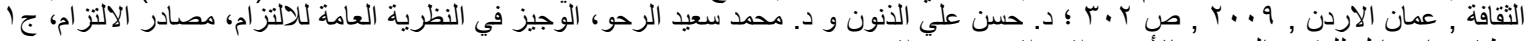

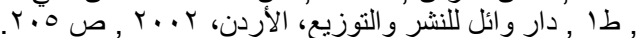

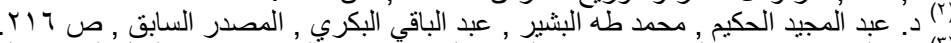

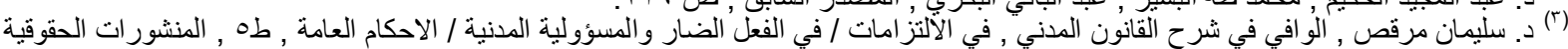

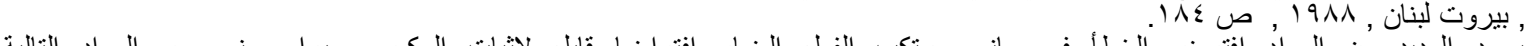

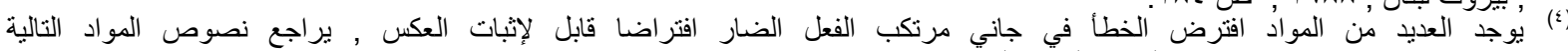

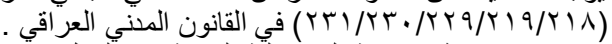

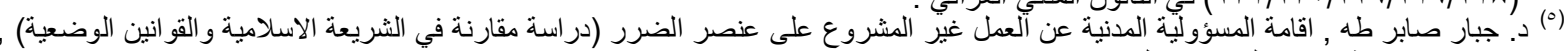

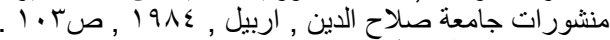

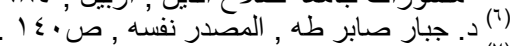

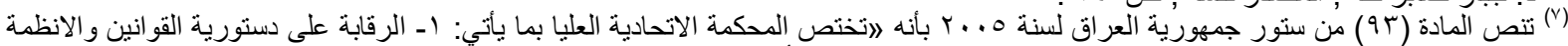

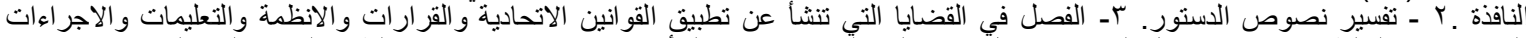

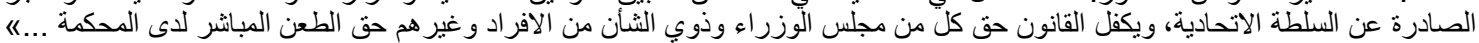




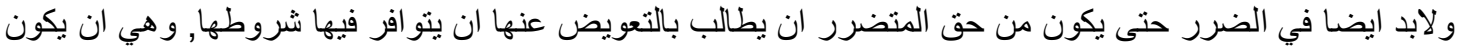

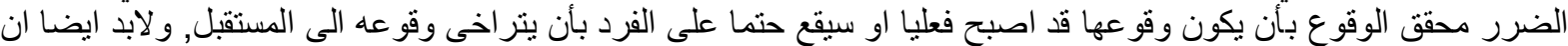

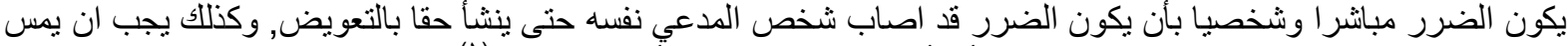

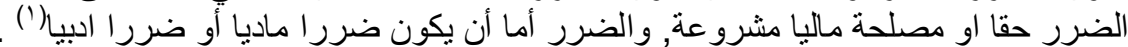

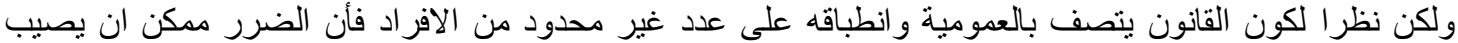

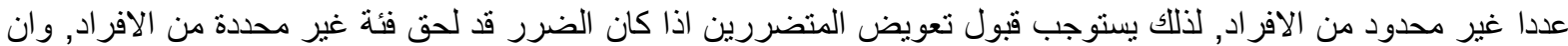

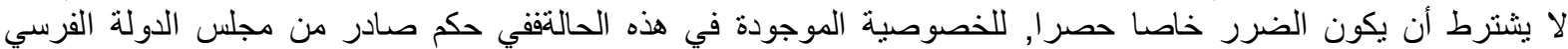

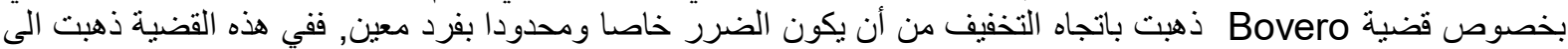

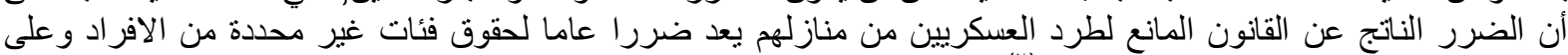

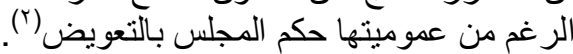
المطلب الثالث

\section{دعوى المسؤولية المشرع المدنية المثنية}

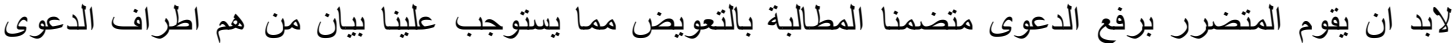

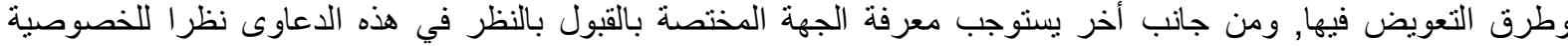

\section{الفرع الأول}

الموجودة في هذه المسؤولية, و هذا ما سنبينه كالآتي :-

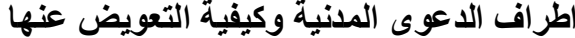

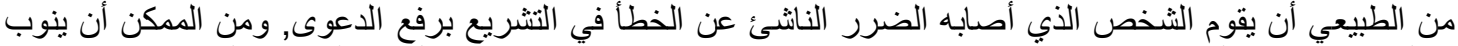

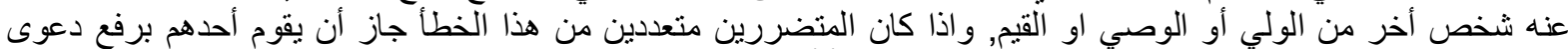

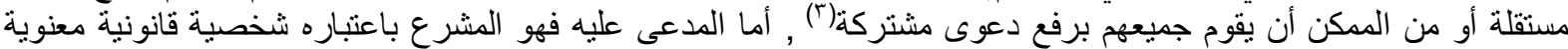

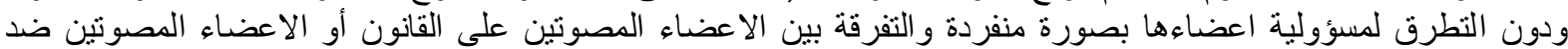

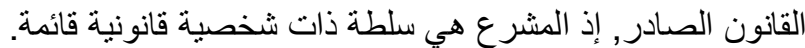

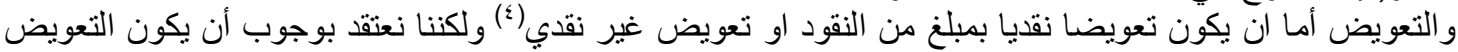

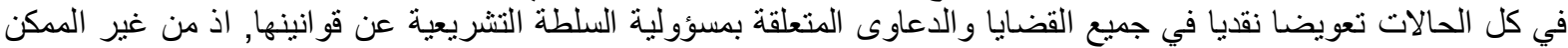

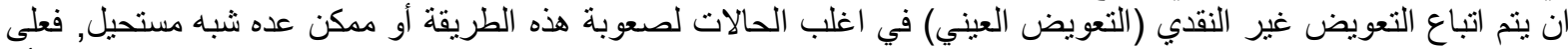

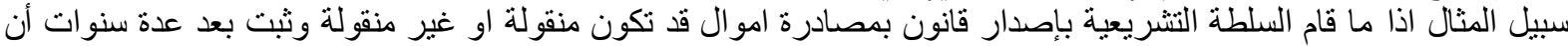

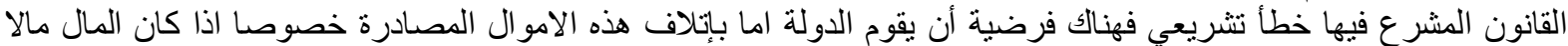

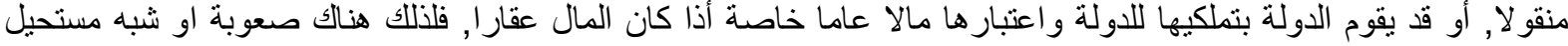

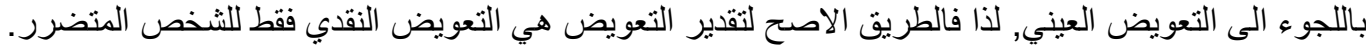

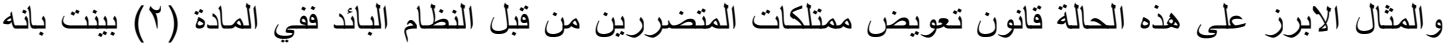

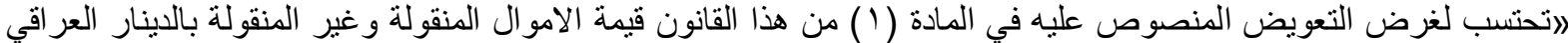

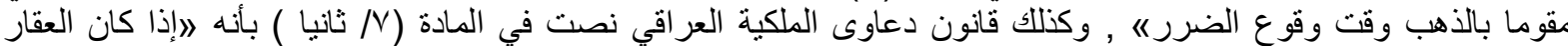

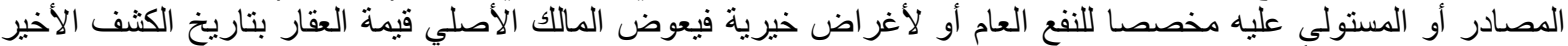

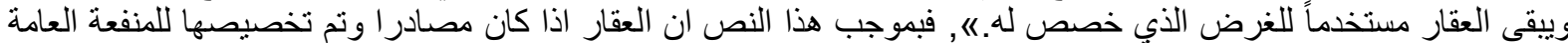

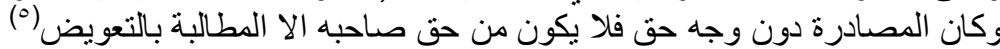

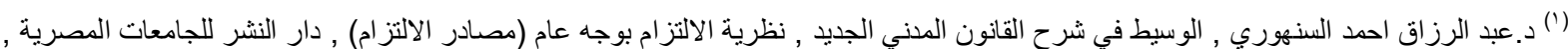

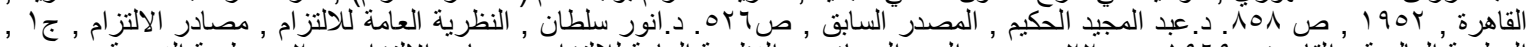

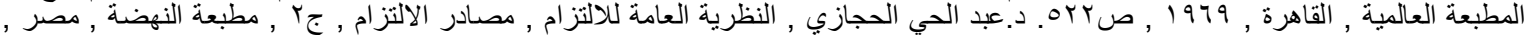

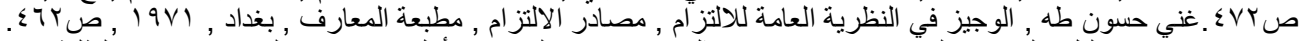

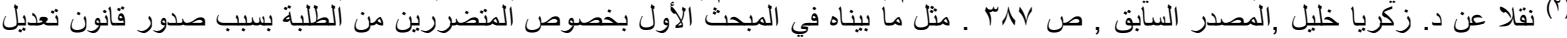

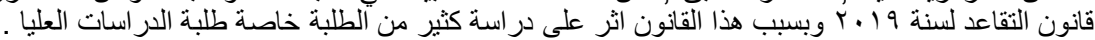

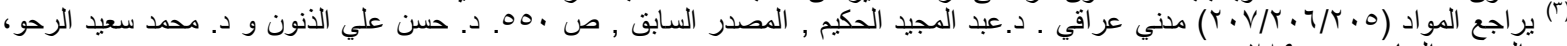

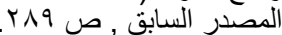

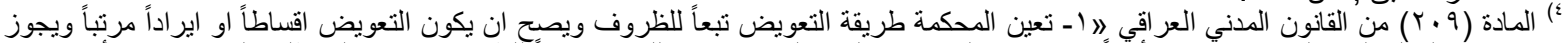

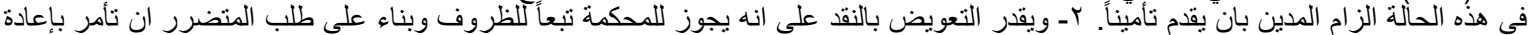

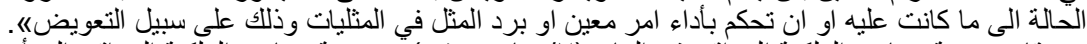

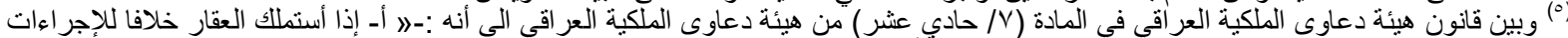

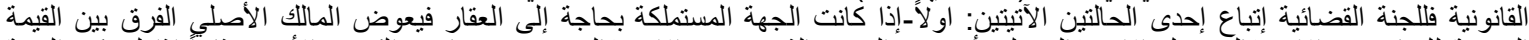

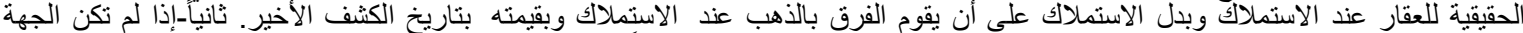

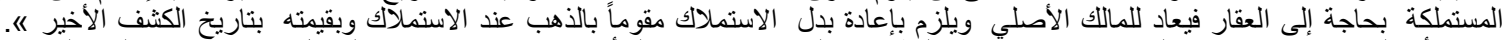

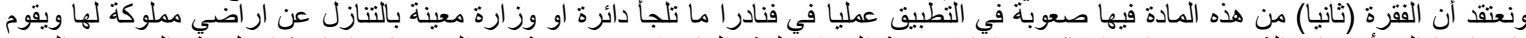

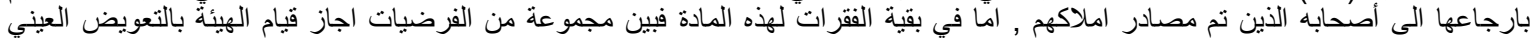

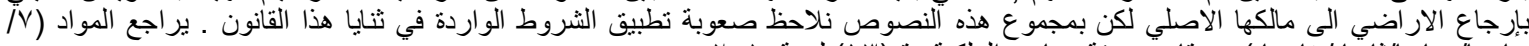

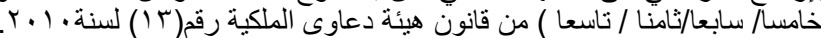




\section{الفرع الثاني (الثي \\ الاختصاص القضائي بنظر الاعوى والطع الطعن فيها}

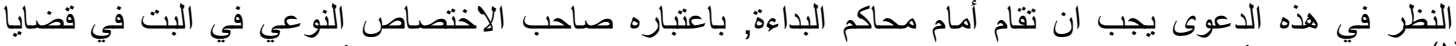

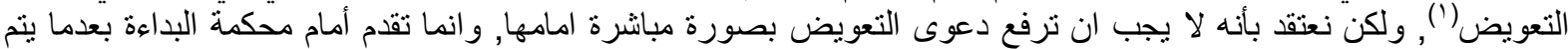

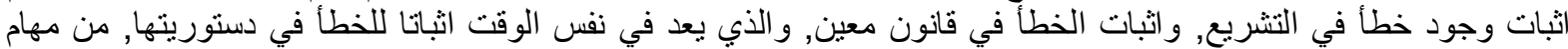

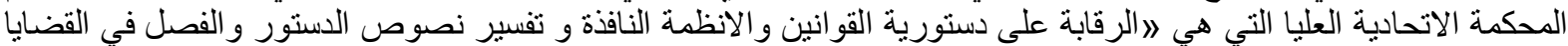

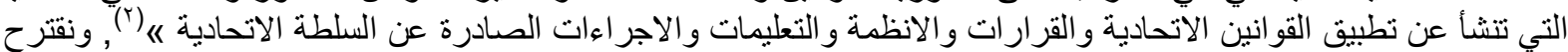

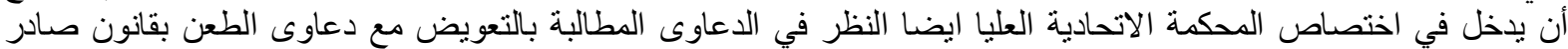

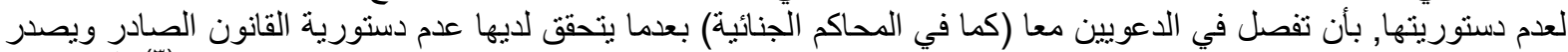

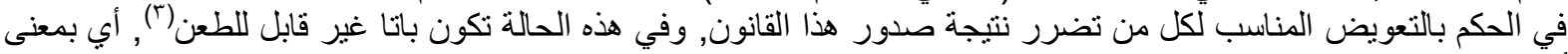

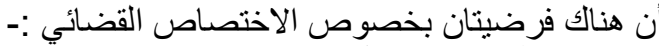

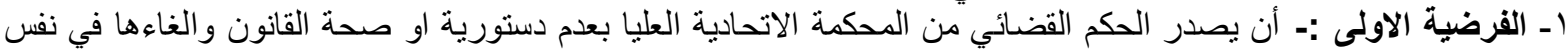

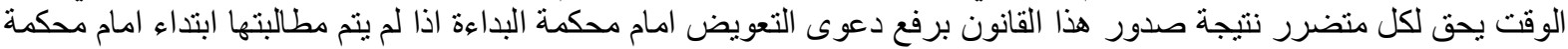

الاتحادية العليا .

r-الفرضية الثانية :- أن بتم ارفاق طلب التعويض بأصل الدعوى المرفوعة أمام المحكمة الاتحادية العلبا الخاصة بطعن القانون

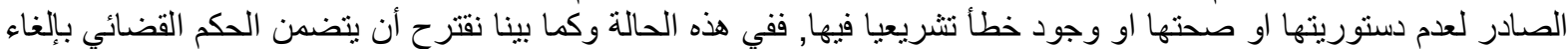

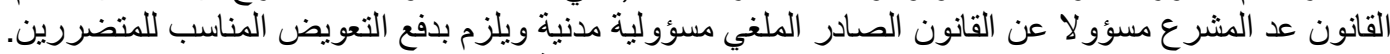
الخاتمة

بعد اتمامنا من هذا البحث نحاول ان نبين أهم النتائج و التوصيات:-

أولا:- النتائج

ا. المشرع هي الجهة التي تمتلك صلاحية اصدار القو اعد القانونية سواء كان التشريع تثريعا عاديا ام فرعيا (الانظمة التعليمات

r r. المشر ع يشمل بشكل عام السلطتين (التشريعية و التنفيذية)

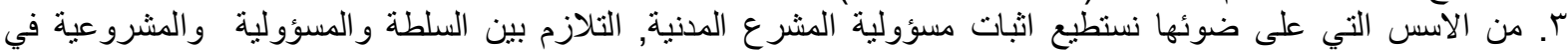

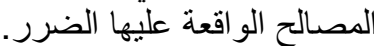
ع. لكي يعد المشرع مسؤو لاً عن اعمالها التشريعية يجب نو افر الثروط التر ان لا يكون هناك مانع قانوني للتعويض, وكذلك يجب ان

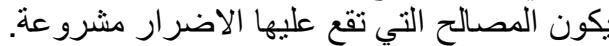

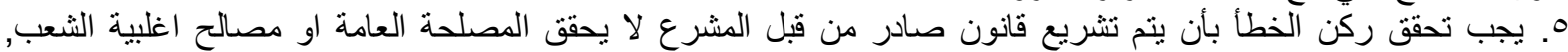

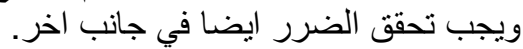

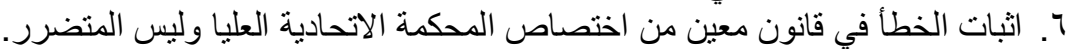

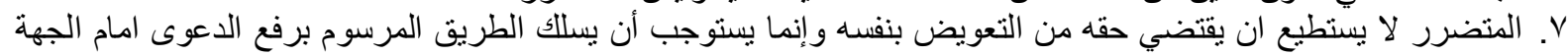

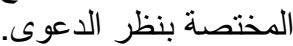

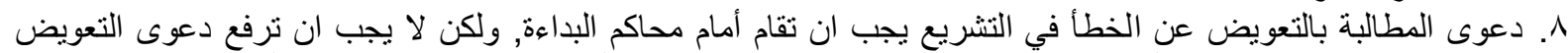

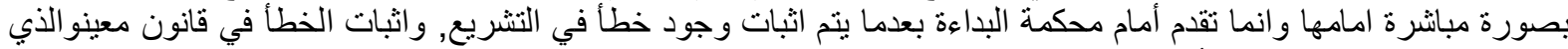

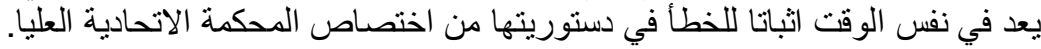
ثانيا :- التوصيات

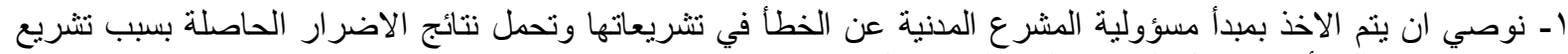

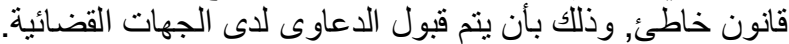

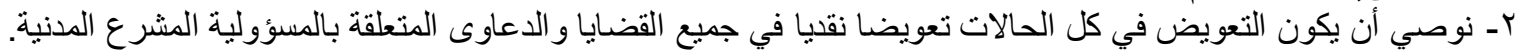

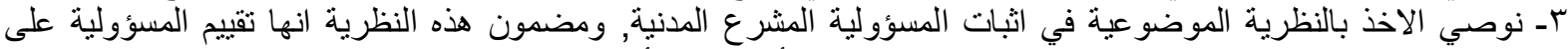

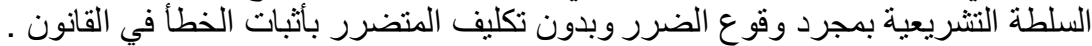

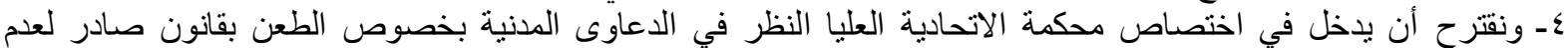
دستوريتها, بأن تفصل في الدعويين معا.

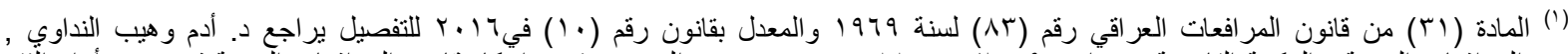

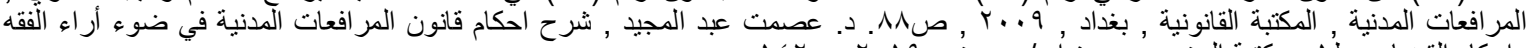

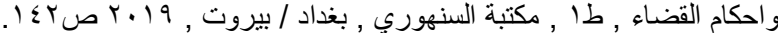

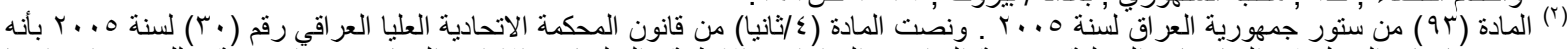

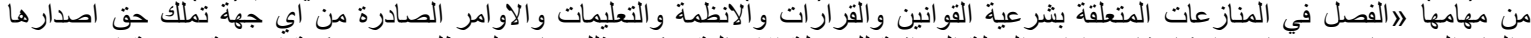

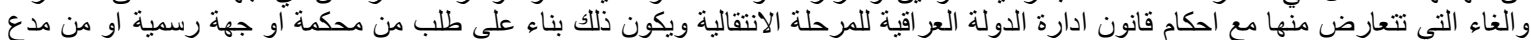


المصادر

أو لا:- الكتب أدم و هيب النداوي, المر افعات المدنية, المكتبة القانونية, بغداد, 9 . . . ب .

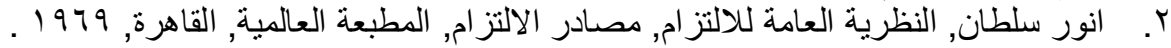

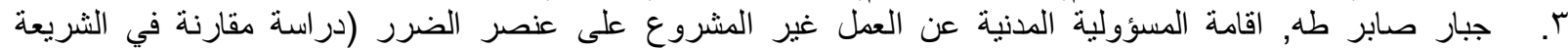

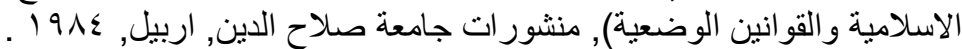

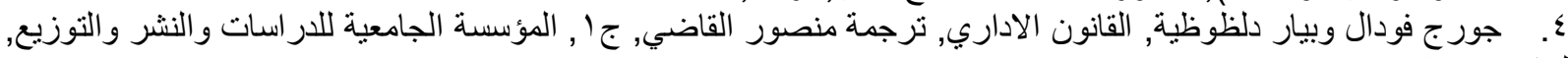
البنان, إ...

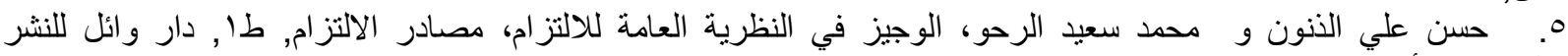

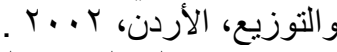

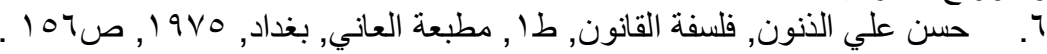

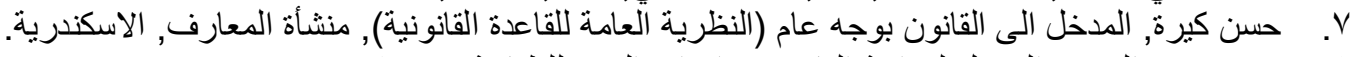

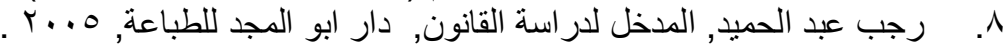

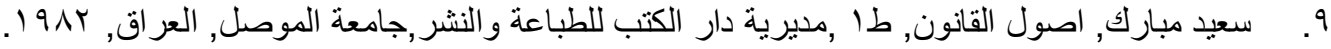

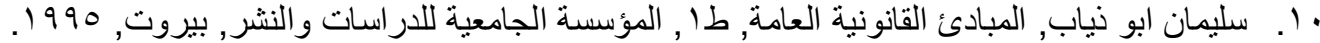

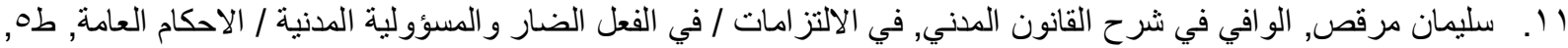

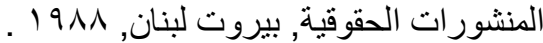

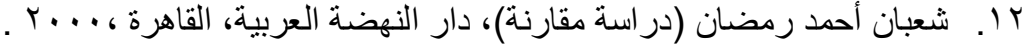

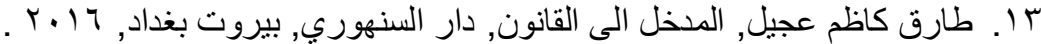

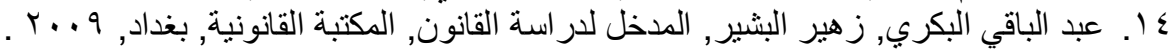

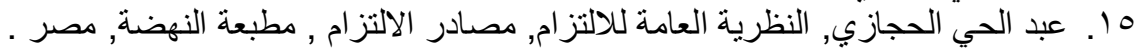

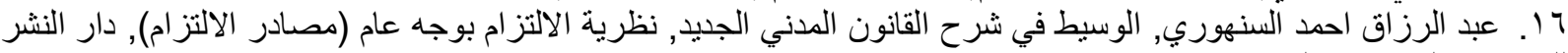

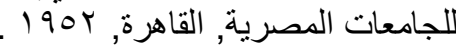

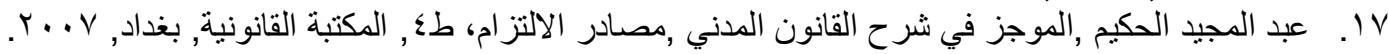

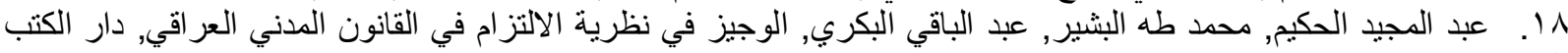

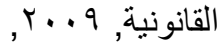
9 19. عدنان ابر اهيم السرحان, نوري حمد خاطر, شرح القانون المدني مصادر الحقوق الثخصية (الالتزامات)، طه, دار الثقافة,

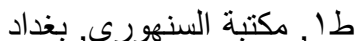

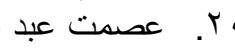

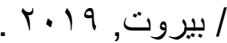

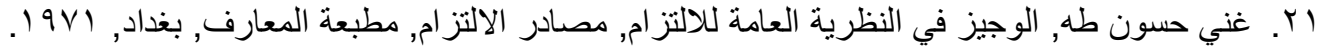

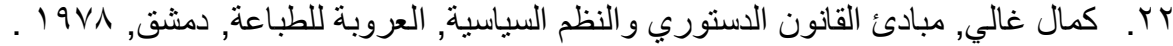

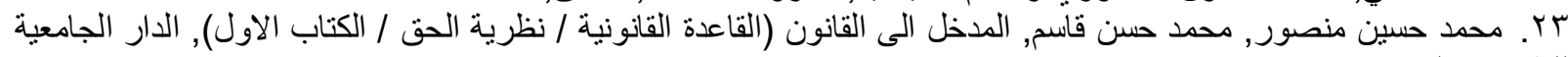

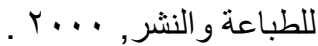

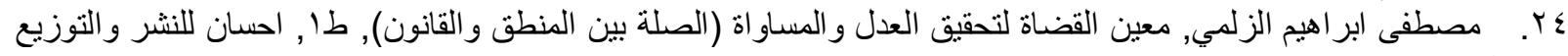

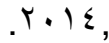

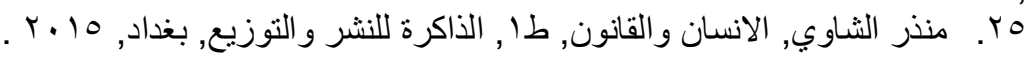

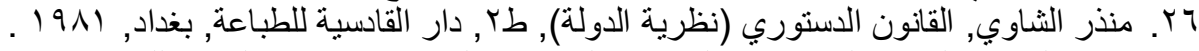

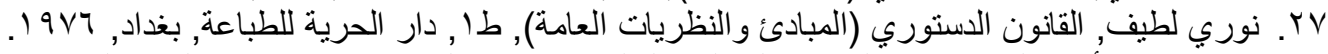

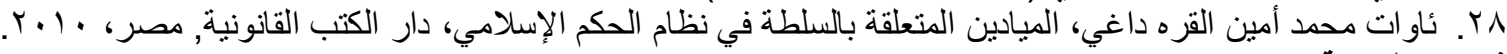
ثانيا:- اطروحة دكتوراه

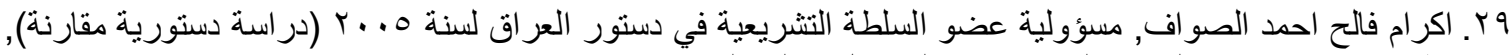

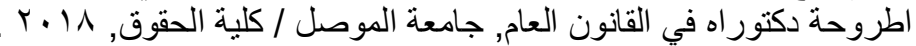
تُاتثا:- البحوث والدراسات

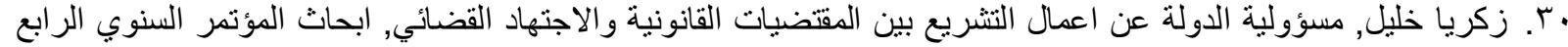

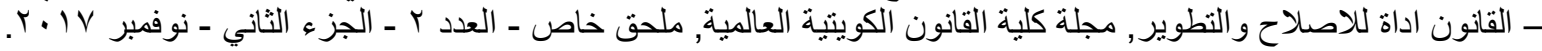

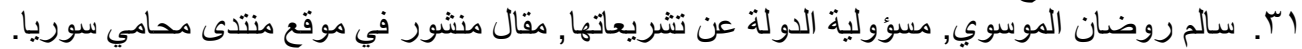

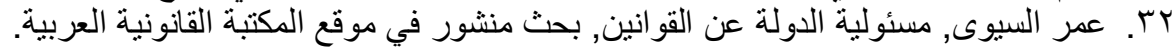

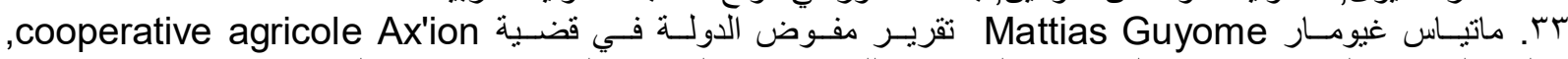

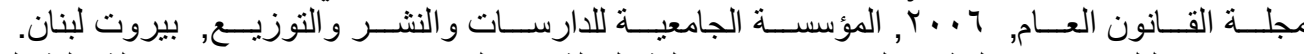
عَr. مازن ليلو راضي, التطور الحديث في مسؤولية الدولة عن القوانين, بحث منشور في مجلة كلية القانون / جامعة النهرين,

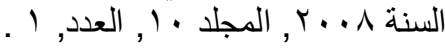




\section{ثُالثا :- القوانين :-

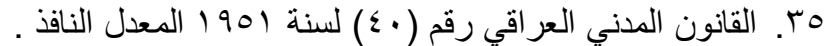

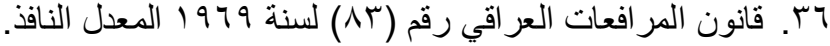

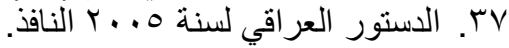

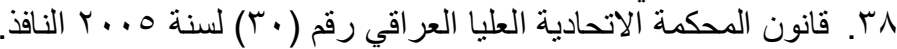

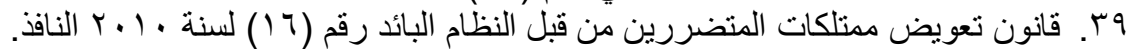

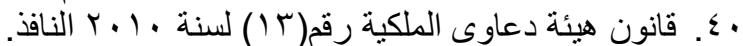

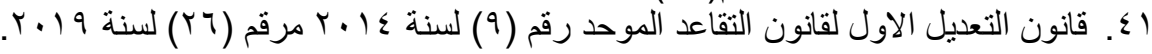

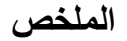

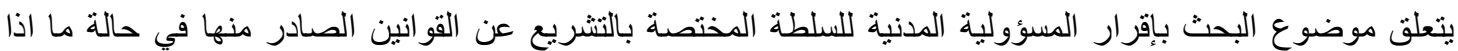

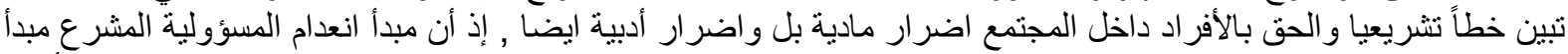

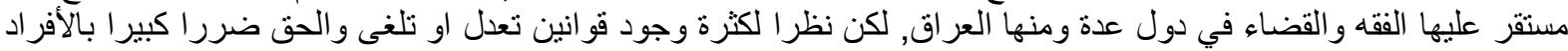

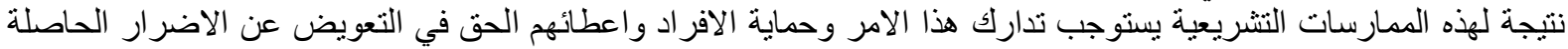

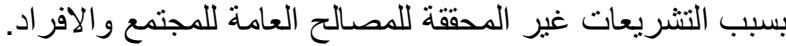

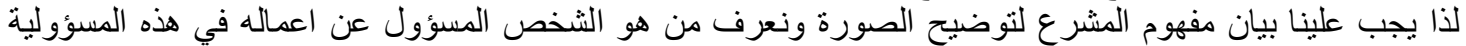

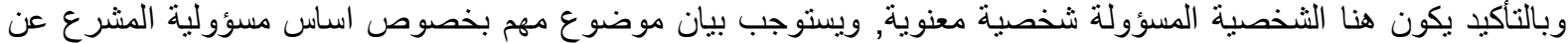

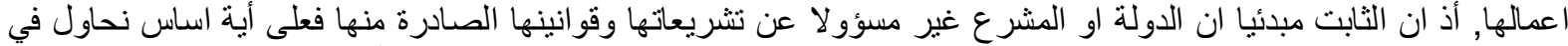

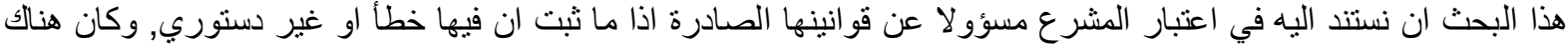

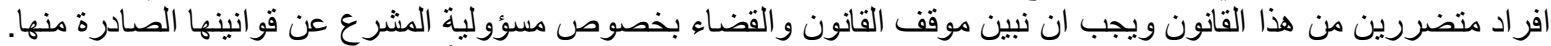

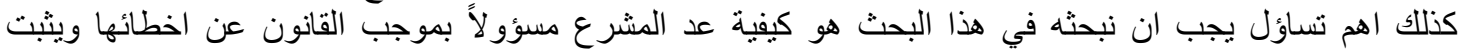

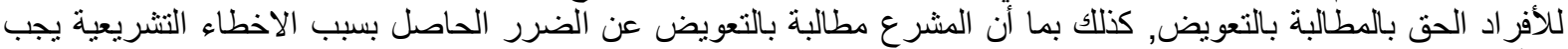

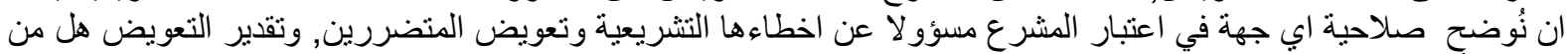

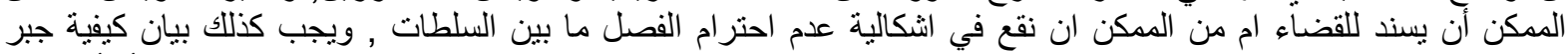

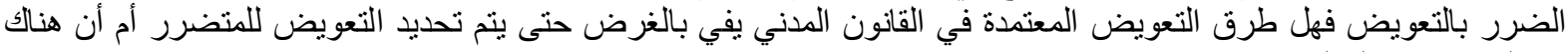

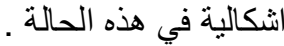
الكلمات المفتاحية:المشرع , التعويض , الخطأ , القانون , الضرر , المسؤولية المدنية. 


\section{Summary}

The subject of the research relates to approving the civil responsibility of the authority competent to legislate the laws issued by it in the event that it shows a legislative line and the right to individuals within society is material and even moral damages, as the principle of lack of responsibility the legislator is a principle based on jurisprudence and the judiciary in several countries, including Iraq, but given the large number of Laws that modify or abolish the right and great harm to individuals as a result of these legislative practices require the remedy of this matter and the protection of individuals and give them the right to compensation for the damage caused due to unfulfilled legislation for the public interests of society and individuals.

Therefore, we must clarify the concept of the legislator to clarify the image and know who is responsible for his actions in this responsibility. Certainly, the person responsible is a moral person, and an important topic must be clarified regarding the basis of the legislator's responsibility for its actions, since the constant in principle is that the state or the legislator is not responsible for its legislation and laws Issued by it, on what basis do we try in this research to rely on it to consider the legislator responsible for its laws issued if it is proven that there is an error or unconstitutionality and there were individuals affected by this law and we must also show examples of the position of the law and the judiciary regarding the legislator's responsibility for its laws Issued from them.

Likewise, the most important question that we must discuss in this research is how the legislator is responsible according to the law for its mistakes and establishes the right to claim compensation, as well as the legislator is required to compensate for the damage caused due to legislative errors, we must clarify the authority of any party to consider the legislator responsible for its legislative errors and compensation Affected, and estimation of compensation Is it possible to be assigned to the judiciary, or is it possible to fall into the problem of lack of respect for separation between the authorities, and it must also be clarified how reparations for compensation are compensated, so are the compensation methods approved in the Civil Code sufficient for the purpose to determine compensation for the injured or is there a problem in This situation.

Keywords: legislator, compensation, error, law, harm, civil liability. 